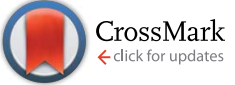

Cite this: RSC Adv., 2017, 7, 16963
Received 7th February 2017 Accepted 13th March 2017 DOI: $10.1039 / \mathrm{c} 7 \mathrm{ra01569k}$ rsc.li/rsc-advances

\section{Nanostructured materials for photodynamic therapy: synthesis, characterization and in vitro activity $\dagger$}

\author{
María E. Alea-Reyes, ${ }^{\text {ab }}$ Mafalda Rodrigues, ${ }^{\text {ab }}$ Albert Serrà, ${ }^{\text {bc }}$ Margarita Mora, ${ }^{d}$ \\ Maria L. Sagristá, ${ }^{d}$ Asensio González, ${ }^{a}$ Sara Durán, ${ }^{e}$ Marta Duch, ${ }^{e}$ José Antonio Plaza, \\ Elisa Vallés, ${ }^{\text {bc }}$ David A. Russell ${ }^{f}$ and Lluïsa Pérez-Garcíał*ab
}

Three nanostructured vehicles are proposed as potential carriers for photosensitizers to be used in photodynamic therapy: spherical nanoparticles, hexahedral microparticles and cylindrical magnetic nanorods. A comparative study of their photodynamic properties was performed, and the influence of their size and the amount of loaded porphyrin was considered to discuss their effects in the observed photodynamic activity. All the vehicles have a gold surface, allowing functionalization with a disulfidecontaining porphyrin as the photosensitizer, as well as with a PEG-containing thiol to improve their biocompatibility and water solubility. The activity of the porphyrin loaded in each vehicle was assessed through in vitro photocytotoxicity studies using HeLa cells. A synergic effect for the porphyrin toxicity was observed in all of the vehicles. The zinc-containing porphyrin showed better production of singlet oxygen, and proved more photocytotoxic both in solution and loaded in any of the vehicles. The magnetism of the nanorods allows targeting with a magnetic field, but causes their aggregation, hampering the porphyrin's activity. Microparticles showed lower cell internalization but their bigger size allowed a high porphyrin loading, which translated into high photocytotoxicity. The highest cell internalization and photocytotoxicity was observed for the porphyrin-loaded nanoparticles, suggesting that a smaller size is favored in cell uptake.

\section{Introduction}

Photodynamic therapy (PDT) is a treatment used in cancer therapy and requires a photosensitizer (PS) molecule, nontoxic in the dark, that when irradiated with visible or near-infrared

\footnotetext{
${ }^{a}$ Departament de Farmacologia, Toxicologia $i$ Química Terapèutica, Universitat de Barcelona, Avda. Joan XXIII 27-31,08028 Barcelona, Spain. E-mail: mlperez@ub.edu ${ }^{b}$ Institut de Nanociència i Nanotecnologia UB (IN2UB), Universitat de Barcelona, Avda. Joan XXIII 27-31, 08028 Barcelona, Spain

${ }^{c}$ Ge-CPN, Departament de Química Física, Universitat de Barcelona, C/ Martí $i$ Franquès 1, 08028 Barcelona, Spain

${ }^{d}$ Departament de Bioquimica i Biologia Molecular, Facultat de Biologia, Universitat de Barcelona, Avda. Diagonal 643, 08028 Barcelona, Spain

eInstituto de Microelectrónica de Barcelona (IMB-CNM (CSIC)), Campus UAB, Cerdanyola, 08193, Barcelona, Spain

${ }^{f}$ School of Chemistry, University of East Anglia, Norwich Research Park, Norwich, Norfolk, NR4 7TJ, UK

$\dagger$ Electronic supplementary information (ESI) available: (1) Synthesis and characterization of the porphyrin derivatives, (2) fabrication of gold coated nanorods and bifunctional microparticles, (3) characterization of the different vehicles loaded with porphyrins, (4) singlet oxygen production, (5) in vitro cytotoxicity, (6) multimedia files: 3D reconstructions of vehicle uptake by HeLa cells. See DOI: $10.1039 / \mathrm{c} 7 \mathrm{ra01569k}$

\$ Present address: School of Pharmacy, The University of Nottingham, University Park, Nottingham NG72RD, England, UK.
}

light produces molecular singlet oxygen that triggers cellular death. ${ }^{1-4}$ Most PSs investigated for PDT applications are chlorins, $^{5,6}$ bacteriochlorins, ${ }^{7}$ phthalocyanines ${ }^{8,9}$ and, especially, porphyrins. ${ }^{10-12}$

PDT presents several advantages: it is less invasive, has fewer secondary effects, and allows more localized treatment. However, some of the major drawbacks of some PSs when used in PDT are the non-specific distribution of the drug in the body as well as the slow excretion of the photosensitizer, leading to severe side effects caused by the patient's exposure to sunlight. Furthermore, some of the currently used PSs are hydrophobic molecules, requiring their dispersion in emulsions or the use of delivery systems to administer the drugs to the biological media. Therefore, the use of nanostructured vehicles to transport and deliver such PSs to the desired target can help to overcome this limitation. ${ }^{13}$ Some examples already described in literature include iron oxide nanoparticles, ${ }^{14,15}$ silica nanoparticles, ${ }^{16,17}$ polymeric nanoparticles, ${ }^{18,19}$ scintillating nanoparticles, ${ }^{20}$ magnetic nanoparticles, ${ }^{14,18,21}$ gold nanowires, ${ }^{22}$ upconverting nanoparticles ${ }^{6,23}$ and gold nanoparticles $(\mathrm{GNP})^{6,24-27}$ as drug delivery systems.

Among these alternatives, research using GNP is very widespread due to their inertness, relatively low toxicity, and facile synthesis and functionalization, ${ }^{24,28-30}$ thus allowing their 
tailoring to target cancer cells, increasing the selectivity of the photosensitizer-vehicle system, and decreasing undesired side effects. Such systems composed of antibody-photosensitizerGNP have showed promising results. ${ }^{31,32}$

Although functionalization of GNP is easy, the conjugation of more than one molecule implies a more complicated procedure. One alternative is the use of Janus type particles, ${ }^{33}$ with different materials that may allow orthogonal chemical functionalization, facilitating the process of immobilizing different functional molecules on the same vehicle. Different alternatives can be used for targeting, as for example using magnetic particles to direct the vehicles to the cancerous tissue through applying a magnetic field, thus moving the particles towards the correct site of action. ${ }^{34}$ This approach has been described for magnetic active targeting of cancer cells using magnetic nanoparticles associated with mesoporous silica nanoparticles ${ }^{35}$ or micro/nanospheres. ${ }^{36}$ Superparamagnetic iron oxide nanoparticles have also been used to cross the blood-brain barrier in order to treat glioma. ${ }^{37}$ One of the key aspects of a vehicle is its size and shape. It was already described that hexahedral silicon oxide microparticles can be easily internalized in HeLa cells. ${ }^{38}$ Furthermore, silica semi-spheres with diameters of 1.6 and 3.2 $\mu \mathrm{m}$ can be internalized in endothelial cells. ${ }^{39}$ Gold nanoparticles with different sizes and aspect ratios have been described to have a better uptake by HeLa cells when the aspect ratio is lower, ${ }^{\mathbf{4 0 , 4 1}}$ but other nanoparticles with different aspect ratios showed a different trend, with a better uptake found for high aspect ratio, ${ }^{\mathbf{4 2 , 4 3}}$ as well as higher internalization rate in the cells. This is explained by the fact that the internalization mechanism appears to depend on the aspect ratio: spherical particles are internalized by clathrin-mediated pathway preferably, while particles with larger aspect ratios tend to internalize by caveolae-mediated pathway. ${ }^{44}$ Therefore, literature suggests that not only the size and shape, but also the composition of the used nanomaterial has influence on the uptake of vehicles into cells, but a clear tendency is not yet well established.

The aim of this work is to study three different types of vehicles as carriers for two disulfide-bearing amidoporphyrins. We select three kinds of carriers for PDT, all presenting a gold surface to favour an easy functionalization with the PS. Each one of these carriers presents a specific characteristic that could be interesting to enhance the efficiency of the PS on PDT:

(1) GNP, widely studied as drug delivery carriers, ${ }^{\mathbf{2 8 , 4 5}}$ have a diameter of few nanometers and should be easily internalized into the cells,

(2) Cobalt-nickel nanorods (NR) with a gold shell and a magnetic core, that have recently been reported to be biocompatible ${ }^{46}$ and useful as drug delivery vehicles, ${ }^{47}$ are easily manipulable and can be targeted by means of a magnetic field, and

(3) Hexahedral Janus microparticles $(\mu \mathrm{P})$ with two different materials (gold and polysilicon) to allow orthogonal functionalization, and that recently have been reported to be biocompatible and internalized by SK-BR-3 and MCF-10A cell lines. ${ }^{\mathbf{4 8 , 4 9}}$

The gold surface present in all the vehicles allows the immobilization of the disulfide-bearing amidoporphyrins. Therefore we describe the synthesis and characterization of two new amidoderivatives of an aminophenylporphyrin and its $\mathrm{Zn}$ analogue using lipoic acid (LA) as linker, their conjugation to the three above-mentioned gold-based vehicles, the physicochemical characterization of the porphyrin-loaded vehicles through different techniques, and their PDT activity, in terms of the singlet oxygen production, as well as their photocytotoxicity and cellular uptake using HeLa cells, in order to select the optimal delivery vehicle for use in PDT.

\section{Experimental}

\section{Materials}

Solvents. Propionic acid, dimethylformamide (DMF), dichloromethane (DCM), methanol (MeOH), chloroform $\left(\mathrm{CHCl}_{3}\right)$ and dimethyl sulfoxide (DMSO) were purchased from Sigma-Aldrich (Germany).

Reagents. Hydroxybenzotriazole monohydrate (HOBT), 3(4,5-dimethylthiazol-2-yl)-2,5-diphenyltetrazolium bromide, 9,10-anthracenediyl-bis(methylene)dimalonic acid (ABMA), (11-mercaptoundecyl)hexa(ethylene glycol) (MHEG), glacial acetic acid, ammonium hydroxide (20\%), benzaldehyde, lipoic acid (LA), nitric acid $\left(\mathrm{HNO}_{3}\right)$, potassium bromide (KBr), pyrrole, sodium bicarbonate, sodium sulfate, tin(II) chloride dihydrate $\left(\mathrm{SnCl}_{2} \cdot 2 \mathrm{H}_{2} \mathrm{O}\right)$, trichloroacetic acid, zinc acetate dihydrate $\left(\mathrm{Zn}(\mathrm{OAc})_{2} \cdot 2 \mathrm{H}_{2} \mathrm{O}\right)$ and sodium borohydride $\left(\mathrm{NaBH}_{4}\right)$, were purchased from Sigma Aldrich (Germany), (6- $\{2-[2-(2-m e t h o x-$ yethoxy)ethoxy]ethoxy\}hexyl)trimethoxysilane (MTMS) was purchased from Sikemia (France), sodium hydroxide (97\%, pellets) and dicyclohexylcarbodiimide (DCC) were purchased from Merck (Germany), hydrochloric acid $6 \mathrm{~N}$ and sulfuric acid (97\%) were purchased from Scharlab (Spain). Dulbecco's Modified Eagle Medium (DMEM) fetal bovine serum (FBS), glucose, L-glutamine, streptomycin sulfate and potassium penicillin were purchased from Gibco-Life Technologies (UK).

\section{Characterization methods}

Melting points were measured by CTP-MP 300 hot-plate apparatus with ASTM 2C thermometer using crystal capillaries purchased from Afora. ${ }^{1} \mathrm{H}-\mathrm{NMR}$ spectra were recorded on a Varian Gemini 300 spectrometer $(300 \mathrm{MHz})$ and on a Varian Mercury 400 spectrometer (400 MHz) from Centres Cientifics $i$ Tecnologics de la Universitat de Barcelona (CCiT-UB). ${ }^{1} \mathrm{H}-\mathrm{NMR}$ spectra were determined using $\mathrm{CDCl}_{3}$ as solvent with TMS (tetramethylsilane) as internal standard. The chemical shifts are expressed in parts per million (ppm) relative to the central peak of the solvent. Matrix Assisted Laser Desorption Ionization-Time of Flight Mass Spectrometry (MALDI-ToF-MS) analyses were performed using a Voyager-DE-RP mass spectrometer (Applied Biosystem, Framingham, USA) and high resolution mass spectra (HRMS) were obtained by electrospray (ESI) on a LC/MSD-ToF mass spectrometer (Agilent Technologies, 2006) from CCiT-UB. MS analysis was operated in the delayed extraction mode using 2,5-dihydroxybenzoic acid (DHB) as a matrix. Thin layer chromatography (TLC) was performed on Merck silica gel plates coated with $\mathrm{F}_{254}$ fluorescent indicator. Column chromatography was carried out on silica gel 60 (Merck 
9385, 230-400 mesh). Elemental analysis was performed on a Thermo EA 1108 CHNS from CCiT-UB. UV-visible absorption spectra were obtained using an UV-1800 Shimadzu UV spectrophotometer, using quartz cuvettes with a $1 \mathrm{~cm}$ path length. Absorption spectra were determined in $\mathrm{CHCl}_{3}$ or water. In general, the compounds were dried overnight at $25{ }^{\circ} \mathrm{C}$ in a desiccator. Fluorescence excitation and emission spectra were recorded using a Hitachi F-4500 fluorescence spectrometer. The spectra were recorded in right angle using quartz cuvettes with a $1 \mathrm{~cm}$ path length. Transmission electron microscopy (TEM) was carried out in the CCiT-UB. The samples were observed with an electronic microscope Tecnai SPIRIT (FEI Co) at $120 \mathrm{kV}$. The images were captured by a Megaview III camera and digitalized with the iTEM program. The size of the gold nanoparticles core was measured with the Analysis software (Olympus). The size of the nanoparticles was also determined by Dynamic Light Scattering (DLS) using a Zetasizer Nano ZS series (Malvern Instruments). Thermogravimetric analysis (TGA) was recorded with a SDT Q600 TA Instrument under $\mathrm{N}_{2}$ atmosphere $\left(\mathrm{N}_{2}\right.$ flow: 50 $\left.\mathrm{mL} \min ^{-1}\right)$. The scanning rate was $5{ }^{\circ} \mathrm{C} \min ^{-1}$ and the temperature range was between 70 and $600{ }^{\circ} \mathrm{C}$ for each sample. Electrochemical experiments have been performed by using a Potentiostat/Galvanostat Autolab PSTAT30, controlled by the GPES program. Cell concentration was calculated using a Luna Automated Cell Counter. Absorbance measurements on microplates were obtained using a microplate reader SynergyMx ${ }^{\mathrm{TM}}$ (BioTek Instruments, Inc.). HeLa cells were imaged by confocal microscopy using a Leica TCS SP2 confocal laser fluorescence microscope (Leica, Heidelberg, Germany) from CCiT-UB, with simultaneously fluorescence and reflection acquisition, by using an argon laser of $488 \mathrm{~nm}$.

\section{Synthesis of ATPP-LA 1 and ATPP-LA}

The synthesis of the precursors of porphyrins ATPP-LA and ZnATPP-LA (TPP, $\mathbf{T P P N O}_{2}, \mathbf{T P P N H}_{2}, \mathbf{Z n T P P N H}_{2}$ ) are explained in detail in the ESI. $\dagger$

Hydroxybenzotriazole monohydrate $(91 \mathrm{mg}, 0.68 \mathrm{mmol})$ and dicyclohexylcarbodiimide (70 $\mathrm{mg}, 0.34 \mathrm{mmol}$ ) were added to a solution of lipoic acid (70 $\mathrm{mg}, 0.34 \mathrm{mmol}$ ) in dry DMF. The solution was cooled down with an ice-water bath and stirred for $1 \mathrm{~h}$. Then a solution of $\mathbf{T P P N H}_{2}(108 \mathrm{mg}, 0.17 \mathrm{mmol})$ in $6 \mathrm{~mL}$ of dry DMF was added and the reaction was stirred at room temperature overnight. After this time, the solvent was evaporated in vacuum. The mixture was washed with a saturated solution of $5 \% \mathrm{NaHCO}_{3}(50 \mathrm{~mL})$. Then the product was extracted with $\mathrm{CHCl}_{3}(2 \times 50 \mathrm{~mL})$, and the organic layer was washed with water $(2 \times 50 \mathrm{~mL})$ and dried over sodium sulfate anhydrous and the organic layer was evaporated under reduced pressure and the crude product purified by column chromatography $\left(\mathrm{SiO}_{2}, \mathrm{DCM}\right)$ to afford a purple solid (125 $\left.\mathrm{mg}, 87 \%\right)$ : m.p. $180{ }^{\circ} \mathrm{C}, \mathrm{rf}=0.44$ in DCM. UV-vis (DCM) $\lambda_{\max } 419,514,552$, 591, $650 \mathrm{~nm}$. The fluorescence emission spectra exhibit two peaks at 655 and $719 \mathrm{~nm}$ (excitation $590 \mathrm{~nm}$ ). ${ }^{1} \mathrm{H}-\mathrm{NMR}$ (400 $\left.\mathrm{MHz} \mathrm{CDCl}_{3}, 25{ }^{\circ} \mathrm{C}\right): \delta \mathrm{ppm}=-2.77(\mathrm{~s}, 2 \mathrm{H},-\mathrm{NH}), 1.95-1.55(\mathrm{~m}$, $\left.8 \mathrm{H}, 4\left(\mathrm{CH}_{2}\right)\right), 2.29-2.23(\mathrm{~m}, 1 \mathrm{H}, \mathrm{CH}), 2.51(\mathrm{t}, J=2.4 \mathrm{~Hz}, 1 \mathrm{H}, \mathrm{CH})$, 2.66-2.60 (m, 1H, CH), 3.60-3.55 (m, 1H, CH), 3.45-3.38 (m, 1H,
$\mathrm{CH}), 4.21-4.18$ (m, 1H, NH), 7.72-7.74 (m, 3H, Ar-H), 8.13 (dd, $J$ $=6.0 \mathrm{~Hz}, J=6.0 \mathrm{~Hz}, 4 \mathrm{H}$, amide phenyl), $8.20(\mathrm{dd}, J=7.0 \mathrm{~Hz}, J=$ $7.0 \mathrm{~Hz}, 8 \mathrm{H}, \beta$-pyrrole), 8.85 (s, 12H, Ar-H). MALDI-ToF-MS: $m / z$ $(\%)=850.2(100)[\mathrm{M}]^{+}$. HMRS (ESI) $\mathrm{m} / \mathrm{z}:\left(\mathrm{C}_{52} \mathrm{H}_{43} \mathrm{~N}_{5} \mathrm{O}_{3} \mathrm{~S}_{2}\right)$ calculated 849.2800 found 850.2880. Elemental analysis found: $\mathrm{N}$, 8.34; C, 73.42; H, 5.18; S, 7.48. Calc. for $\mathrm{C}_{52} \mathrm{H}_{43} \mathrm{~N}_{5} \mathrm{O}_{3} \mathrm{~S}_{2}$ : N, 8.24; C, 73.47; H, 5.10; S, 7.54\%. Then a solution of ATPP-LA $125 \mathrm{mg}$, $0.025 \mathrm{mmol})$ in DCM $(5 \mathrm{~mL})$ was added to a stirred solution of $\mathrm{NaBH}_{4}(7.5 \mathrm{mg}, 0.198 \mathrm{mmol})$ in water $(1.0 \mathrm{~mL})$. The mixture was stirred at room temperature overnight. The phases were separated and the organic phase was washed with water $(3 \times 50 \mathrm{~mL})$, then dried over sodium sulfate anhydrous and concentrated under vacuum to give ATPP-LA as a purple solid (21 $\mathrm{mg}, 84 \%$ ). UV-vis $\lambda_{\max }(\mathrm{DCM}) / \mathrm{nm} 419,517,554,590$ and 652 . The fluorescence emission spectra exhibit two peaks at 652 and $709 \mathrm{~nm}$ (excitation $590 \mathrm{~nm}$ ). Due to instability of the porphyrin ATPP-LA which results in its oxidation, ATPP-LA was used in situ in the functionalization of the three different vehicles.

\section{Synthesis of ZnATPP-LA}

Hydroxybenzotriazole monohydrate $(43 \mathrm{mg}, 0.35 \mathrm{mmol})$ and dicyclohexylcarbodiimide (36 $\mathrm{mg}, 0.17 \mathrm{mmol})$ were added to a solution of lipoic acid (36 mg, $0.17 \mathrm{mmol}$ ) in dry DMF. The solution was stirred at ice water bath temperature for $1 \mathrm{~h}$. Then a solution of $\mathbf{Z n T P P N H}_{2}$ (61 $\mathrm{mg}, 0.08 \mathrm{mmol}$ ) in dry DMF (3 mL) was added. The reaction was stirred at room temperature overnight. The solvent is evaporated in vacuum. The mixture was washed with a saturated solution of $5 \% \mathrm{NaHCO}_{3}(50 \mathrm{~mL})$. Then the product was extracted with DCM $(2 \times 50 \mathrm{~mL})$, and the organic layer was washed with water $(2 \times 50 \mathrm{~mL})$ and dried over sodium sulfate anhydrous and the organic layer was evaporated under reduced pressure and the crude product purified by column chromatography $\left(\mathrm{SiO}_{2}, \mathrm{DCM}\right)$ to afford a purple solid (69 mg, 93\%): m.p. $180{ }^{\circ} \mathrm{C}, \mathrm{rf}=0.40$ in DCM. UV-vis (DCM) $\lambda_{\max }$ $420,541,588 \mathrm{~nm}$. The fluorescence emission spectra exhibit two peaks at 600 and $650 \mathrm{~nm}$ (excitation at 550). ${ }^{1} \mathrm{H}-\mathrm{NMR}(400 \mathrm{MHz}$, $\left.\mathrm{CDCl}_{3}, 25{ }^{\circ} \mathrm{C}\right): \delta \mathrm{ppm}=1.42-1.10\left(\mathrm{~m}, 8 \mathrm{H}, \mathrm{CH}_{2}\right), 1.57(\mathrm{t}, J=$ $1.2 \mathrm{~Hz}, 1 \mathrm{H}, \mathrm{CH}), 2.21-2.18(\mathrm{~m}, 1 \mathrm{H}, \mathrm{CH}), 1.63-1.60(\mathrm{~m}, 1 \mathrm{H}, \mathrm{CH})$, 2.79-2.74 (m, 1H, CH), 3.16-3.14 (m, 1H, NH), 2.92-2.88 (m, 1H, $\mathrm{CH}), 7.12(\mathrm{~d}, J=3.4 \mathrm{~Hz}, 2 \mathrm{H}$, amide phenyl), 7.74-7.71 (m, 9H, Ar-H), 8.00 (d, $J=3.8 \mathrm{~Hz}, 2 \mathrm{H}$, amide phenyl), 8.22-8.20 (m, 6H, Ar-H), 8.86 (d, $J=4.2 \mathrm{~Hz}, 2 \mathrm{H}, \beta$-pyrrole), 8.92 (d, $J=4.3 \mathrm{~Hz}, 2 \mathrm{H}$, $\beta$-pyrrole), 8.94 (s, 4H, $\beta$-pyrrole). MALDI-ToF-MS: $m / z(\%)=$ 879.2 (100) $[\mathrm{M}]^{+}$. HMRS (ESI) $m / z:\left(\mathrm{C}_{52} \mathrm{H}_{41} \mathrm{~N}_{5} \mathrm{OS}_{2} \mathrm{Zn}\right)$ calculated 879.2000 found 879.2045 .

\section{Synthesis and characterization of gold nanoparticles (GNP) with ATPP-LA (ATPP-LA-GNP) and ZnATPP-LA (ZnATPP-LA- GNP)}

A solution of $\mathrm{HAuCl}_{4} \cdot 3 \mathrm{H}_{2} \mathrm{O}(2.0 \mathrm{mg}, 0.005 \mathrm{mmol})$ in water (1 $\mathrm{mL}$ ) was added to a stirred solution of ATPP-LA (4.1 mg, 0.005 $\mathrm{mmol})$ in $\mathrm{CHCl}_{3}(0.5 \mathrm{~mL})$ or ZnATPP-LA $(4.3 \mathrm{mg}, 0.005 \mathrm{mmol})$ in $\mathrm{CH}_{2} \mathrm{Cl}_{2}(0.5 \mathrm{~mL})$. The thiol MHEG $(2.3 \mathrm{mg}, 0.009 \mathrm{mmol})$ was dissolved in water $(1 \mathrm{~mL})$ and the solution was added to the mixture under vigorous stirring. An excess of $\mathrm{NaBH}_{4}(5.6 \mathrm{mg}$, $0.148 \mathrm{mmol})$ or $(2.8 \mathrm{mg}, 0.074 \mathrm{mmol})$ in water $(1 \mathrm{~mL})$ was added 
dropwise to the corresponding mixture. The stirring continued for $24 \mathrm{~h}$ in the dark at room temperature. GNP were obtained in aqueous phase. The phases were separated using an extraction funnel and the solvent of the aqueous phase was removed in a rotary evaporator, followed by multiple washings with water and $\mathrm{CHCl}_{3}(3 \times 1 \mathrm{~mL})$ using centrifugation $(14000 \mathrm{rpm}, 17 \mathrm{~min}$ at $15{ }^{\circ} \mathrm{C}$ ). The water-soluble GNP containing the porphyrin ATPP-LA were named as ATPP-LA-GNP and the GNP containing the porphyrin ZnATPP-LA were named as ATPP-LA-GNP.

\section{Functionalization of nanorods (NR)}

The nanorods (NR) used in this study were obtained as described elsewhere, ${ }^{46}$ and are composed of a magnetic core made of cobalt and nickel covered by a gold shell. Three different NR-based samples were prepared: a control sample containing MHEG-functionalized NR (PEG-NR), a sample with MHEG and ATPP-LA (ATPP-LA-NR), and a sample with MHEG and ZnATPP-LA (ZnATPP-LA-NR). The functionalization was performed as follows: for the preparation of the control sample PEG-NR, $200 \mu \mathrm{M}$ of MHEG in DMSO $(1 \mathrm{~mL})$ was added to a vial containing $450 \mu \mathrm{g}$ of dry NR; for the preparation of ATPP-LA-NR and ZnATPP-LA-NR samples, $1 \mathrm{~mL}$ of a solution containing 200 $\mu \mathrm{M}$ of MHEG and $20 \mu \mathrm{M}$ of porphyrin ATPP-LA or ZnATPP-LA in DMSO was added, respectively to a vial containing $450 \mu \mathrm{g}$ of dry NR. For characterization purpose, control NR identified as NR$\mathrm{H}$ and NR-Zn, containing the porphyrin ATPP-LA or ZnATPP-LA respectively, but no PEG, were also prepared as follows: $20 \mu \mathrm{M}$ of the corresponding porphyrin in DMSO $(1 \mathrm{~mL})$ were added to a vial containing $450 \mu \mathrm{g}$ of dry NR. Before starting the incubation, and at 2-3 hours intervals, the vials were sonicated to favour the homogeneity of the suspensions of the NR. The samples were left in incubation for 48 hours, after which the NR were washed $(5 \times 1 \mathrm{~mL})$ with $\mathrm{DMSO}$, by suspending with ultrasounds and then by removing the solvent using a magnet to trap the NR. The NR were then washed once with $1 \mathrm{~mL}$ of ethanol and dried.

The functionalization of the NR was corroborated by means of three experimental techniques: fluorescence microscopy, TGA and electrochemical probe experiments. TGA was carried out in order to establish the amount of loaded porphyrin, and to evaluate the thermal stability of the functionalized NR. Cyclic voltammetries of the $\mathrm{Fe}(\mathrm{II}) / \mathrm{Fe}(\mathrm{III})$ system in a $2 \mathrm{mM} \mathrm{K}_{4}\left[\mathrm{Fe}(\mathrm{CN})_{6}\right]+$ $2 \mathrm{mM} \mathrm{K}_{3}\left[\mathrm{Fe}(\mathrm{CN})_{6}\right]+\mathrm{KNO}_{3} \quad 0.2 \mathrm{M}$ solution (electrochemical probe) were recorded in order to detect possible variations in the profiles of NR functionalized with porphyrins respect to that of non-functionalized NR. Before each experiment, $2.5 \mu \mathrm{L}$ of suspensions of functionalized and non-functionalized NR in mixtures of water : ethanol $(4: 1)$ were dropped on the surface of a glassy carbon rod (electrodes of $0.0314 \mathrm{~cm}^{2}$ ) and then were dried under a nitrogen flow.

\section{Functionalization of microparticles $(\mu \mathrm{P})$}

The microparticles $(\mu \mathrm{P})$ used in this study were prepared as described elsewhere $;^{48}$ and consist of a layer of polysilicon and a layer of gold attached by a thin chromium layer. Three different samples were prepared: a control sample containing
MTMS and MHEG (PEG- $\mu$ P), a sample with MTMS and ATPP-LA (ATPP-LA- $\boldsymbol{\mu P}$ ), and a sample with MTMS and ZnATPP-LA (ZnATPP-LA- $\mu$ P). The functionalization was performed as follows: $100 \mu \mathrm{L}$ of piranha solution were added to a microtube, containing approximately $10^{6}$ microparticles, and the microparticles were incubated for 1 hour at room temperature with continuous shaking at $400 \mathrm{rpm}$. The suspensions were then centrifuged for 15 minutes at $13500 \mathrm{rpm}$, washed twice with MilliQ water $(1 \mathrm{~mL})$ and once with DMSO $(1 \mathrm{~mL})$. For control microparticles PEG- $\mu$ P, $100 \mu \mathrm{L}$ of a MHEG solution in DMSO (6 $\mathrm{mM}$ ) were added. For microparticles with the porphyrins ATPPLA- $\mu$ P and ZnATPP-LA- $\mu$ P $100 \mu$ L of solutions of the porphyrins ATPP-LA or ZnATPP-LA in DMSO (1.2 mM) were added, respectively. The suspensions of microparticles with MHEG or with porphyrins were left for 48 hours at room temperature in a shaker at $400 \mathrm{rpm}$. Then they were centrifuged for 15 minutes at $13500 \mathrm{rpm}$. The supernatant was recovered for porphyrin determination and the $\mu \mathrm{P}$ were washed twice with DMSO (1 $\mathrm{mL}$ ). Then, the surface containing polysilicon was functionalized by incubating with $100 \mu \mathrm{L}$ of $10 \%$ MTMS in DMSO for 2 hours at room temperature, after which they were centrifuged for 15 minutes at $1350 \mathrm{rpm}$ and washed twice with DMSO $(1 \mathrm{~mL})$ and twice with ethanol $(1 \mathrm{~mL})$ and air dried and then suspended in $10 \mu \mathrm{L}$ of culture medium (DMEM) to calculate the final concentration of $\mu \mathrm{P}$ using a Neubauer Chamber and counting the particles with an optical microscope.

\section{Singlet oxygen production of the ATPP-LA, ATPP-LA, ZnATPP- LA, ATPP-LA-GNP and ZnATPP-LA-GNP}

Singlet oxygen formation can be monitored indirectly through the conversion of ABMA into an endoperoxide which can be detected by fluorescence spectroscopy. Briefly, $3 \mu \mathrm{L}$ of a solution $5.12 \times 10^{-4} \mathrm{M}$ of ABMA in $\mathrm{MeOH}$ were added to the cuvettes containing $(3.93 \mu \mathrm{L}, 3.84 \mu \mathrm{L}$ or $4.07 \mu \mathrm{L})$ of ATPP-LA 1 , ATPP-LA or ZnATPP-LA solutions in DMSO respectively, to give a final concentration of porphyrin in the cuvette of $3 \mu \mathrm{M}$. In the case of the GNP, $3 \mu \mathrm{L}$ of ABMA $\left(5.12 \times 10^{-4} \mathrm{M}\right.$ in $\left.\mathrm{MeOH}\right)$ were added to cuvettes containing $(512 \mu \mathrm{L}$ or $384 \mu \mathrm{L})$ of aqueous solutions of ATPP-LA-GNP or ZnATPP-LA-GNP respectively, to give the same concentration of ATPP-LA or ZnATTP-LA $(3 \mu \mathrm{M})$. The solutions were added to a quartz cuvette and stirred thoroughly. A light source with a range between $400 \mathrm{~nm}$ and $500 \mathrm{~nm}$ was used to irradiate the stirred solutions during 4 hours. Fluorescence spectra were recorded every hour, in the range of 390-600 nm, and the singlet oxygen production was determined by the decrease of the fluorescence intensity of ABMA.

\section{Cytotoxicity and photocytotoxicity studies}

HeLa cells (human cervical adenocarcinoma cells; ATCC CCL-2) were used to test the cytotoxicity and the photocytototoxicity of the different porphyrins ( $\mathbf{T P P N H}_{2}$ and $\mathbf{Z n T P P N H}_{2}$ ) and the controls of the carriers (GNP, NR and $\mu \mathrm{P}$ ) and loaded with the porphyrins (ATPP-LA-GNP, ZnATPP-LA-GNP, ATPP-LA-NR, ZnATPP-LA-NR, ATPP-LA- $\mu$ P and ZnATPP-LA- $\boldsymbol{\mu P}$ ). HeLa cells were cultured at $37{ }^{\circ} \mathrm{C}$ in a humidified sterile atmosphere of 95\% air and 5\% $\mathrm{CO}_{2}$, using DMEM supplemented with FBS 
$(10 \% \mathrm{v} / \mathrm{v})$, glucose $\left(4.5 \mathrm{~g} \mathrm{~L}^{-1}\right)$, L-glutamine $\left(292 \mathrm{mg} \mathrm{L}^{-1}\right)$, streptomycin sulphate $\left(50 \mathrm{mg} \mathrm{L}^{-1}\right)$ and potassium penicillin $(50000$ $\mathrm{U} \mathrm{L}^{-1}$ ). For cytotoxicity studies, cells were seeded in 96-well plates ( 3300 cells per well) and grown up to $70-85 \%$ confluence. Cells were then incubated for 24 hours with different concentrations of the porphyrins in solution $(0-100 \mu \mathrm{M})$, each vehicle control: (0-150 $\mu \mathrm{g} \mathrm{mL}^{-1}$ of NR; 0-100 $\mathrm{nM}$ of GNP); 0-400 $000 \mu \mathrm{P}$ $\left.\mathrm{mL}^{-1}\right)$ or each vehicle loaded with either porphyrin $(0-20.8 \mu \mathrm{g}$ $\mathrm{mL}^{-1}$ of NR; $0-100 \mathrm{nM}$ of GNP; $\left.0-400000 \mu \mathrm{P} \mathrm{mL} L^{-1}\right)$. Cells incubated with the complete medium in the absence of vehicles were used as control. After incubation, the medium was discarded, cells were washed three times with cold PBS and incubation was followed for 24 additional hours with fresh culture medium. Cell viability was determined by means of the MTT assay. Briefly, the remaining HeLa cells were incubated with a MTT solution $\left(0.05 \mathrm{mg} \mathrm{mL}^{-1}\right)$ in complete DMEM for 3 hours. The medium was discarded, formazan crystals were solubilized with pure DMSO and the formazan concentration was determined by absorption at $526 \mathrm{~nm}$. Cell viability was determined by the ratio between the absorbance of treated cells and that of non-treated cells (control, $100 \%$ viability).

For photocytotoxicity studies, cells were incubated with porphyrins or with the porphyrin-loaded vehicles for $24 \mathrm{~h}$, washed three times with cold PBS and feed with fresh complete medium and then were irradiated using a LED source (LED par 64 Short, ShowTec) of a wavelength range of $515 \pm 50 \mathrm{~nm}$, with a light intensity at the irradiation site of $6 \mathrm{~mW} \mathrm{~cm}^{-2}$. Samples were irradiated at different times ranging from $2 \mathrm{~min}$ to $32 \mathrm{~min}$ to achieve the intended light fluence. Cells were again incubated for $24 \mathrm{~h}$ in the dark and the reduction in cell viability was also determined by means of the MTT assay.

\section{Internalization study of the different vehicles}

Confocal microscopy was used to verify ZnATPP-LA-GNP, ZnATPP-LA-NR and ZnATPP-LA- $\mu$ P internalization. Cells were grown in an 8 wells Chamber Coverglass Nunc Lab-Tek II. First, cells were incubated at $37^{\circ} \mathrm{C}$ for $24 \mathrm{~h}$ with a suspension of the corresponding ZnATPP-LA-loaded carrier in DMEM (15 nM ZnATPP-LA-GNP, $15.6 \mu \mathrm{g} \mathrm{mL} \mathrm{mL}^{-1}$ ZnATPP-LA-NR and 60000 ZnATPP-LA- $\mu$ P $\mathrm{ml}^{-1}$ ) to allow their internalization. The concentrations used for each vehicle were chosen in order to have the maximum amount of the vehicle in solution that allows a HeLa cell viability (in the dark) above $80 \%$. To confirm the intracellular localization of the carriers, the cytoplasm of the cells was labelled with the CellTracker ${ }^{\mathrm{TM}}$ fluorescent probe Green CMFDA (5-chloromethylfluorescein diacetate) in serumfree culture medium, which acts as a cytoplasm cell tracker (C7025 Thermo Fisher, Life Technologies). The methodology of the labelling process consists in the following steps: (1) cells were washed twice for $5 \mathrm{~min}$ with PBS (1 mL), (2) incubated for $30 \mathrm{~min}$ at $37^{\circ} \mathrm{C}$ with the binding solution $(5 \mu \mathrm{M}$ CMFDA in serum-free culture medium) ( $2 \mathrm{~mL}$ ), (3) washed twice for $5 \mathrm{~min}$ with PBS $(1 \mathrm{~mL}),(4)$ incubated for 30 additional min at $37{ }^{\circ} \mathrm{C}$ with supplemented cell culture medium; and (5) lastly washed twice for 5 min with PBS (1 mL). After labelling, the cells were maintained in complete culture medium containing $10 \mathrm{mM}$
HEPES to keep cells alive during its observation with the microscope. HeLa cells were imaged using a Leica TCS SP2 confocal laser fluorescence microscope (Leica, Heidelberg, Germany) with simultaneously fluorescence and reflection acquisition, to detect the cell marker and the vehicles respectively, by using an argon laser of $488 \mathrm{~nm}$. Different sections were initially scanned, and a data set of $z$-series images were collected from the bottom of the wells toward the top in the $z$ axis direction. Three-dimensional reconstructions were made with the software Imaris 7.2.3 (Bitplane AG, USA).

\section{Results and discussion}

\section{Synthesis and characterization of porphyrin-functionalized GNP, NR and $\mu$ P}

In this work, the main objective was to incorporate two porphyrins, one of them containing a metal in its core, in different nanostructured materials with a gold shell in order to understand the influence that size, morphology and composition has in their bio-photoactivity, and therefore select the best carriers to be used as delivery vehicles for PDT. In order to do so, we used a multidisciplinary approach combining synthesis of nanomaterials, microfabrication, surface chemical functionalization and cell biology studies (cytotoxicity and photocytotoxicity, cellular internalization), to prepare hybrid nanostructured materials capable to interact with living cells, and deliver photoactive drugs. Prior to the materials functionalization, porphyrin derivatives adequate to immobilization in the potential vehicles had to be synthetized. The characterization of the disulphide-bearing amidoporphyrins ATPP-LA and ZnATPP-LA (Fig. 1) and the synthesis and characterization of their precursors ${ }^{50-53}$ can be found in Section 1 in ESI (detailed synthetic procedure and characterization, Schemes S1, S2 and Fig. S1-S16). $\dagger$ LA was chosen in this work to act as linker for the correct immobilization of the porphyrins (ATPP-LA and ZnATPP-LA) in the vehicles, because this compound is commonly used for electrochemical studies of biomolecules or for the elaboration of biological sensors ${ }^{54,55}$ and coupled to a porphyrin. ${ }^{56}$

Due to instability of the porphyrin ATPP-LA which results in its oxidation, ATPP-LA was used in situ in the functionalization of the three different vehicles.

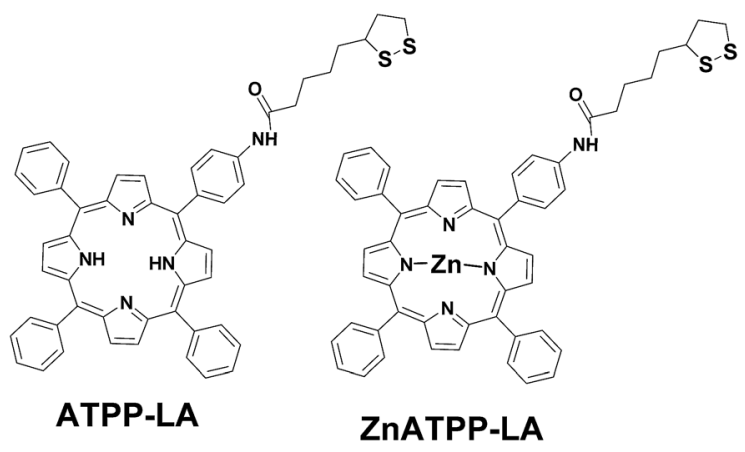

Fig. 1 Structure of the porphyrins ATPP-LA and ZnATPP-LA. 
The synthesized porphyrins ATPP-LA and ZnATPP-LA were conjugated to three different vehicles, each with different characteristics given by their corresponding materials and dimensions, that can help improve their therapeutic effect. Therefore, we chose to study:

(1) GNP, widely studied as vehicles for different types of therapy, can easily enter the cells due to their small size, and due to a high area/volume ratio allow a high loading of porphyrin molecules on their surface; ${ }^{45,57,58}$

(2) biocompatible CoNi NR covered with a gold layer, ${ }^{46}$ that confers inertness to the system and allows a facile functionalization, while the CoNi core renders them magnetic, making possible to direct the vehicle by applying a magnetic field, thus avoiding side effects caused by non-specific distribution of the PS in the organism; and

(3) biocompatible Janus $\mu \mathrm{P}$ with two different materials (gold and polysilicon) with dimensions in the micrometric scale. These $\mu \mathrm{P}$ can be internalized by cells, ${ }^{49}$ and the presence of two surfaces from different materials can be used to functionalize each of the surfaces with different molecules, ${ }^{48}$ such as the PS in one face and a targeting molecule or a hydrophilic molecule such as polyethyleneglycol (PEG) on the other face.

From these materials, the gold nanoparticles are synthesized in situ in the presence of the porphyrins while the microparticles and the nanorods are fabricated prior to the immobilization of the porphyrins, through processes already described. The magnetic CoNi core of the NR is electrochemically grown in a polycarbonate membrane, which is later dissolved, and the released NR are then covered with a gold layer through galvanic displacement (see ESI Fig. S17† for their preparation). ${ }^{46}$ The $\mu \mathrm{P}$ composed of gold and polysilicon surfaces are fabricated through photolithography: the polysilicon layer is deposited on top of a sacrificial layer, then a chromium layer (to help the adhesion between the polysilicon and the gold), and finally the gold layer is deposited (see ESI Fig. S18 $\uparrow$ for microfabrication details). ${ }^{48}$ Fig. 2 shows the SEM images of the NR and the microparticles, prior to functionalization, depicting their shape, dimensions and surface composition. Each of these vehicles has a specific characteristic: the GNP have high area/ volume ratio, the NR have a magnetic CoNi core useful to direct these carriers to the tumour tissue, and the $\mu \mathrm{P}$ have a gold surface and a polysilicon surface that can be used to immobilize different molecules.

According to literature, some metals can affect the formation of singlet oxygen by porphyrins and, consequently, their photodynamic effect when these metals are coordinated in the

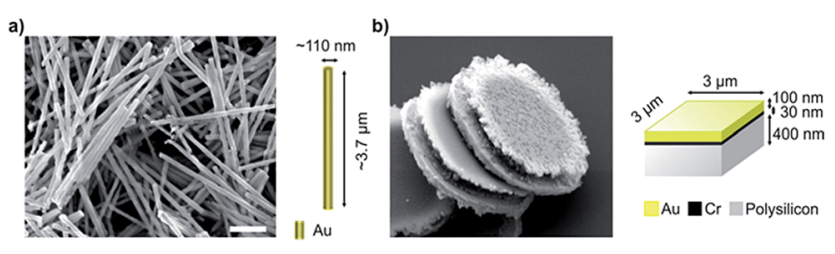

Fig. 2 SEM image and schematic representation of (a) nanorods and (b) microparticles, with their corresponding dimensions and surface composition. core of the porphyrin ring. In this study we use the same porphyrin with and without $\mathrm{Zn}$ in their core. Apart from the $\mathrm{Zn}$, the only metal found in the proximity of the porphyrin is gold but it is not part of the porphyrin molecule and the linkage of the porphyrin with the gold shell is the same for all the vehicles. $\mathrm{Co}$ and $\mathrm{Ni}$ are in the core of the nanorods, and therefore they are not in contact with the porphyrin, and $\mathrm{Cr}$ is present as a thin layer between gold and polysilicon in the microparticles, as a "cement" to attach the two materials, and is not in contact with the porphyrin because the molecules are immobilized on the gold surface.

For each vehicle (GNP, NR or $\mu \mathrm{P}$ ), due to their differences in material composition, size, morphology and preparation method, different methodologies were used for the functionalization with the porphyrins ATPP-LA and ZnATPP-LA, and consequently the distribution of the molecules on the surface is expected to be different. Fig. 3 shows the schematic representation of each nanostructure containing the porphyrins, as well as a PEG-derivative used to increase the water dispersability of the hybrid nanomaterials.
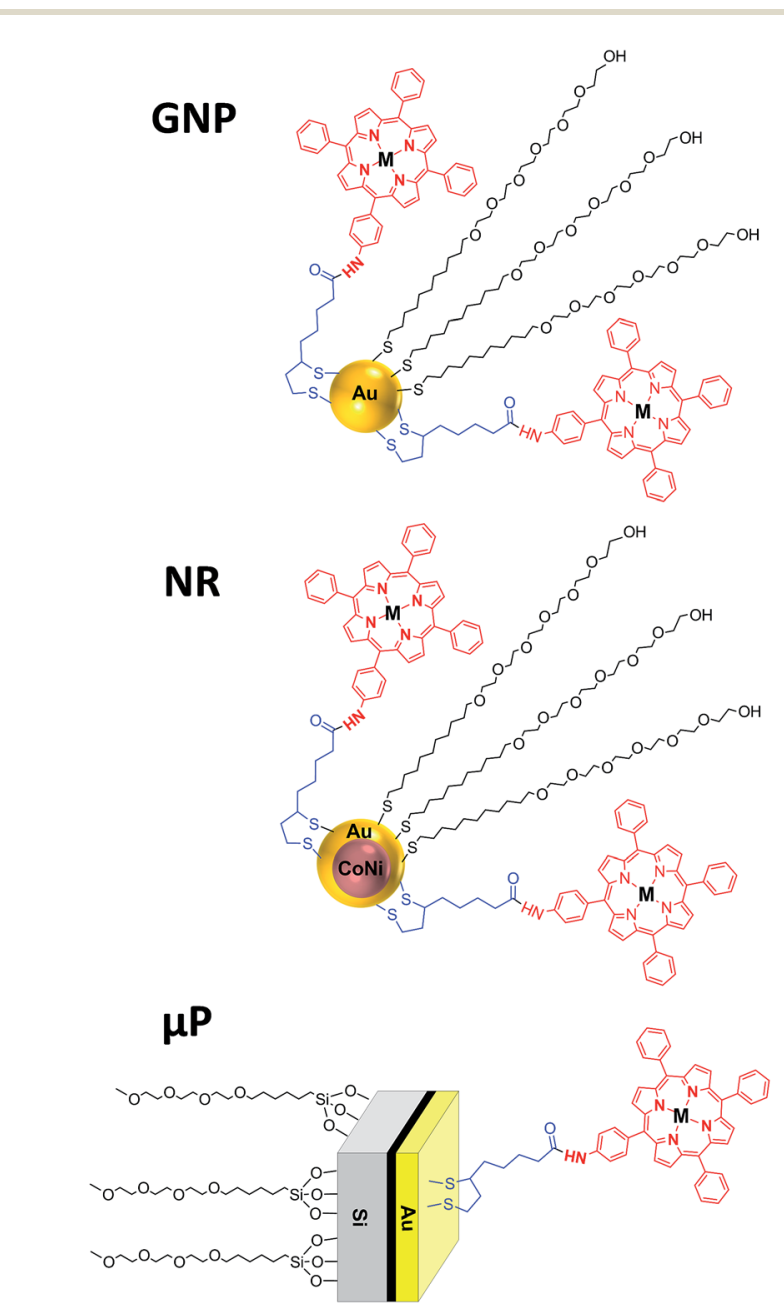

Fig. 3 Schematic representation (cross-section) of GNP: ATPP-LAGNP $(M=H, H)$ and ZnATPP-LA-GNP $(M=Z n)$, NR: ATPP-LA-NR $(M=$ $H, H)$ and $Z n A T P P-L A-N R(M=Z n)$, and $\mu P$ : ATPP-LA- $\mu P(M=H, H)$ and ZnATPP-LA- $\mu P(M=Z n)$. 
In the case of the GNP, the synthesis was adapted from the Brust-Schiffrin biphasic method ${ }^{59}$ and was performed in the presence of the disulphide-bearing amidoporphyrin derivatives ATPP-LA or ZnATPP-LA, so that the final GNP already incorporated these porphyrins in their structure. To make the GNP more hydrophilic and biocompatible, 11-mercaptoundecyl) hexa(ethylene) glycol (MHEG) was also introduced. The initial molar ratio between the MHEG and the porphyrin used was $2: 1$. The $\mathrm{S}-\mathrm{S}$ bond is sensitive to the presence of reducing agents such as $\mathrm{NaBH}_{4}$ (used for GNP synthesis). ${ }^{60}$ For this reason, to avoid a competition between the reduction of the gold salt and LA, we decided to use an excess of $\mathrm{NaBH}_{4}$ in the synthesis of GNP to ensure the reduction of the gold salt. LA is consequently also reduced by $\mathrm{NaBH}_{4}$ to dihydrolipoic acid (DHLA), which have also been proven to be a valuable ligand for stabilizing and inhibiting the aggregation of GNP. ${ }^{61,62}$

The newly synthesized GNP were characterized by Transmission Electron Microscopy (TEM) and Dynamic Light Scattering (DLS) in the preparation medium, in order to determine their size, morphology and size distribution. Fig. 4 shows the TEM micrographs obtained for both synthesized ATPP-LA-GNP and ZnATPP-LA-GNP, and their respective distribution histograms. In both cases, the obtained GNP, loaded with the amidodisulfide porphyrin derivative and the PEG-derivative MHEG, presented spherical shape and are monodisperse, with narrow size distribution. The GNP gold core has an average diameter of $\mathbf{9 . 5} \pm \mathbf{1 . 5} \mathrm{nm}$ and $10 \pm 1.3 \mathrm{~nm}$ for ATPP-LA-GNP and ZnATPP-LAGNP respectively, as measured by TEM, and hydrodynamic diameter of $13.0 \pm 0.8 \mathrm{~nm}$ and $13.5 \pm 1.0 \mathrm{~nm}$ for ATPP-LA-GNP and ZnATPP-LA-GNP respectively, as measured by DLS, which takes into account the organic shell composed by the thiol ligands used to stabilize the GNP. DLS analysis also showed that these GNP are stable in solution and present low polydispersity index between 0.11-0.13. Furthermore, when the carriers were added to the culture medium no turbidities appear that could indicate the formation of aggregates. ${ }^{63}$

Fluorescence spectroscopy was used to confirm the presence of the two synthesized porphyrins ATPP-LA and ZnATPP-LA on
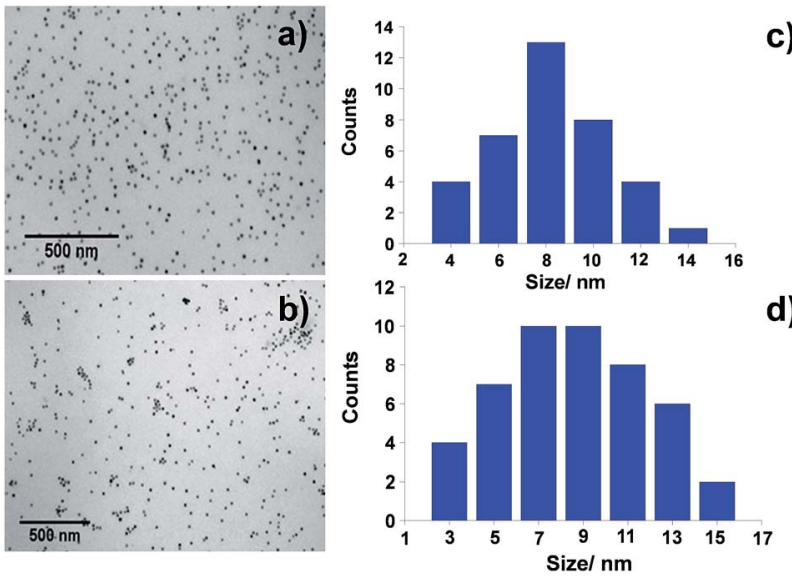

Fig. 4 TEM micrographs of (a) ATPP-LA-GNP and (b) ZnATPP-LAGNP and ( $c$ and $d$ ) size distribution histograms of both GNP respectively. the GNP surface thanks to the ability of the porphyrins to emit fluorescence. ${ }^{64}$ The fluorescence emission spectra were recorded for the free porphyrins (ATPP-LA and ZnATPP-LA) in $\mathbf{C H C l}_{3}$ solution and for the porphyrin-coated GNP in aqueous solution (see ESI Fig. S19 and S20†). The fluorescence emission spectra of the metal-free porphyrin ATPP-LA and of the ATPP-LA-GNP exhibit two peaks at $c a . \lambda 652$ and $709 \mathrm{~nm}$ (excitation at $590 \mathrm{~nm}$ ) as it was expected for the non-metallated porphyrin derivatives (see ESI Fig. S20 $\dagger$ ), ${ }^{64}$ while in the case of the metallated porphyrin ZnATPP-LA and ZnATPP-LA-GNP the fluorescence emission spectra of both samples exhibit two peaks at $c a . \lambda 600$ and $650 \mathrm{~nm}$ (excitation at $550 \mathrm{~nm}$ ) as expected for Zn-porphyrin derivatives (see ESI Fig. S20 $){ }^{65}$ These results indicate the immobilization of both porphyrins (ATPP-LA and ZnATPP-LA) into GNP, and also demonstrate that the fluorescence emission of the photosensitizer is not affected significantly when the porphyrin is linked to the GNP.

Through UV-visible absorption spectroscopy it was possible to confirm the presence of the porphyrins in the synthesized GNP (see ESI Fig. S21 $\dagger$ ) and quantify the total amount of immobilized porphyrin in the GNP using the porphyrins' characteristic Soret band and the $\mathrm{Q}$ bands present in the absorption spectra. To calculate the extinction coefficient of the porphyrins, a calibration curve was obtained in the range 0.5-10 $\mu \mathrm{M}$ for both ATPP-LA and ZnATPP-LA (see ESI, Fig. S22 and S23 $\dagger$ ). GNP concentration was determined applying calculations described by Haiss, ${ }^{\mathbf{6}}$ and the amount of porphyrins per GNP was then calculated. The ratio of incorporated porphyrin per nanoparticle was found to be $1.67 \times 10^{4}$ ATPP-LA molecules per GNP and $2.81 \times 10^{3}$ ZnATPP-LA molecules per GNP (see ESI Table $\mathrm{S} 1 \uparrow$ for details).

In the case of the NR, an initial ratio of $10: 1 \mathrm{MHEG} /$ porphyrin was used (see Fig. 5a): the porphyrin used is hydrophobic and the material also has low water dispersability. Therefore, we used a higher ratio of MHEG than the one used for the GNP, to increase the dispersability in water of the porphyrin-loaded NR, but still maintaining a high porphyrin content. The successful immobilization of the porphyrins on their gold surface was assessed by fluorescence microscopy, since porphyrin-functionalized NR should present red coloured fluorescence. Fig. 5b and c show images of naked NR, and Fig. 5d and e of the porphyrin-functionalized NR ATPP-LA-NR and ZnATPP-LA-NR respectively, with visible red coloured fluorescence of the porphyrin, confirming its presence linked to the NR surface. The NR, being magnetic, have a natural tendency to aggregate, fact that was favoured due to the necessity of drying the sample for observation in the microscope. Furthermore, NR functionalization was confirmed using electrochemical characterization. Control NR containing the porphyrin ATPP-LA or ZnATPP-LA, but no PEG-derivative (MHEG), were also prepared, and identified as NR-H and NR$\mathrm{Zn}$, respectively. The functionalization was corroborated by comparing the electrochemical probe of $\mathrm{Fe}(\mathrm{II}) / \mathrm{Fe}(\mathrm{III})$ redox couple response of non-functionalized (NR) and functionalized (ATPP-LA-NR, ZnATPP-LA-NR, PEG-NR, NR-H and NR-Zn) NR. The results are shown in Fig. $5 \mathrm{f}$. 

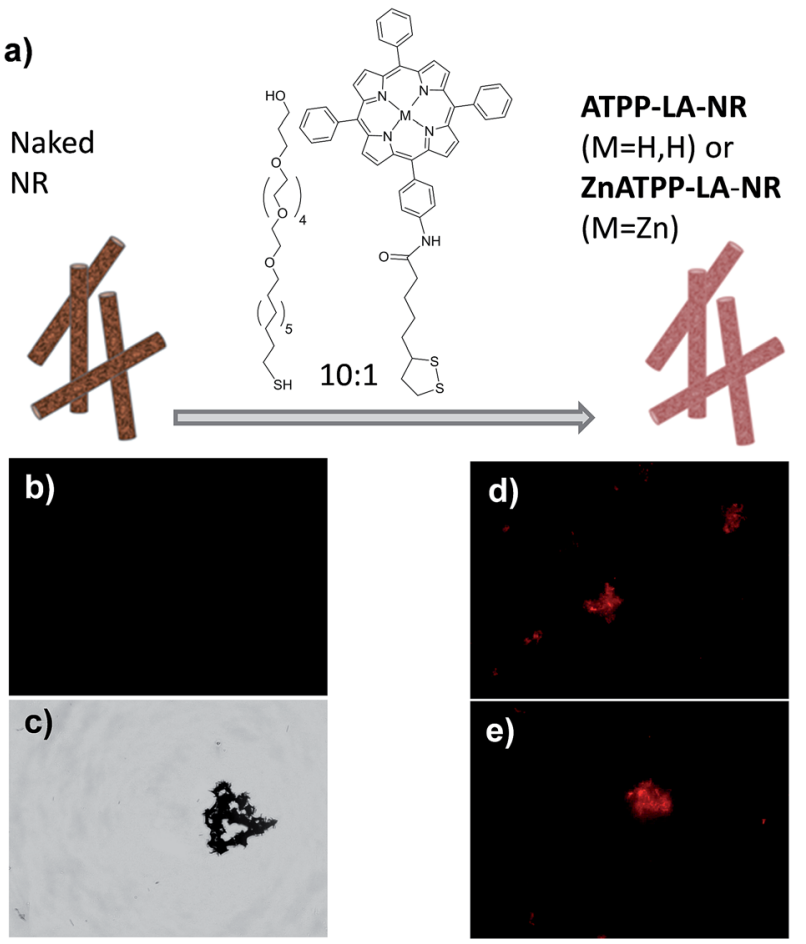

f)

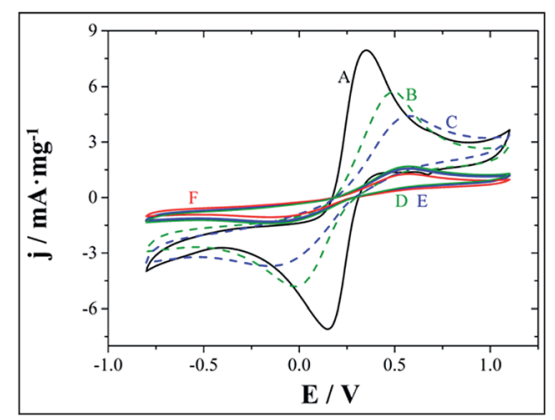

Fig. 5 Schematic representation of the NR functionalization with either ATTP-LA or ZnATPP-LA (a); fluorescence microscope images showing a mesh of non-functionalized naked NR (b) and the corresponding image with visible light (c); fluorescence microscope images showing a mesh of porphyrin-functionalized ATPP-LA-NR (d) and ZnATPP-LA-NR (e), identified by the red color. Magnification 400x; Electrochemical probe of $\mathrm{Fe}\left(\right.$ (I)/Fe(II) system at $100 \mathrm{mV} \mathrm{s}^{-1}$ (f) showing curves for non-functionalized naked NR (A), NR-H (B), NR-Zn (C), ATPP-LA-NR (D), ZnATPP-LA-NR (E) and PEG-NR (F).

As expected, the formation of an organic layer on the NR surface creates an additional barrier on the electrode, which results in a decrease in peak mass-normalized current density $\left(j_{\mathrm{p}}\right)$, while peak-to-peak separation $\left(\Delta E_{\mathrm{p}}\right)$ increases. Thus, there is a significant decrease in peak mass-normalized current density and increase in the separation of the peaks when NR were functionalized with porphyrins ATPP-LA and ZnATPP-LA and without MHEG (NR-H and NR-Zn, respectively) (curves B and $\mathrm{C}$ respect to curve $\mathrm{A}$ ), with a blocking effect slightly higher in the case of NR-Zn. Therefore, the electrochemical tests clearly show that NR could be easily functionalized with both porphyrins and PEG-derivative.

Because NR scatter light when in suspension, it was not possible to quantify the amount of porphyrin by measuring the
UV-visible absorption spectra of the samples. Measuring the amount of porphyrin remaining in the supernatant did not provide good results either. Therefore, the amount of loaded porphyrin per mass of NR and the thermal stabilities of the nonfunctionalized and functionalized samples were evaluated by thermogravimetric analysis (see ESI Fig. S24†). The amounts found per mg of NR were $0.011 \mu \mathrm{mol}$ of ATPP-LA in ATPP-LA-NR and $0.016 \mu \mathrm{mol}$ of ZnATPP-LA in ZnATPP-LA-NR.

For the immobilization of the porphyrins in the $\mu \mathrm{P}$, because these particles have two surfaces, each of a different material, they must be functionalized in a sequential manner as described elsewhere ${ }^{48}$ (see Fig. 6a).

First, the gold surface was functionalized with the porphyrin (ATPP-LA or ZnATPP-LA) and then the polysilicon surface was functionalized with a silane derivative containing polyethyleneglycol groups, namely (6-\{2-[2-(2-methoxyethoxy) ethoxy] ethoxy\}hexyl)trimethoxysilane (MTMS), to improve the water solubility and biocompatibility (see ESI, Scheme S3†). The presence of the porphyrins on the microparticles, indicating their successful immobilization, was assessed by fluorescence microscopy. The functionalized microparticles show a red bright fluorescence observed due to the presence of the porphyrins. Furthermore, they show homogeneous fluorescence intensity and no significant differences were observed between the immobilized microparticles with porphyrins ATPPLA or ZnATPP-LA (Fig. $6 \mathrm{~b}$ and c, respectively). The amount of porphyrin immobilized in the functionalized microparticles was determined indirectly using UV-visible absorption spectroscopy, by calculating the difference between the initial amount of porphyrin in solution and the final amount present after incubation with the vehicles, using the calibration curves

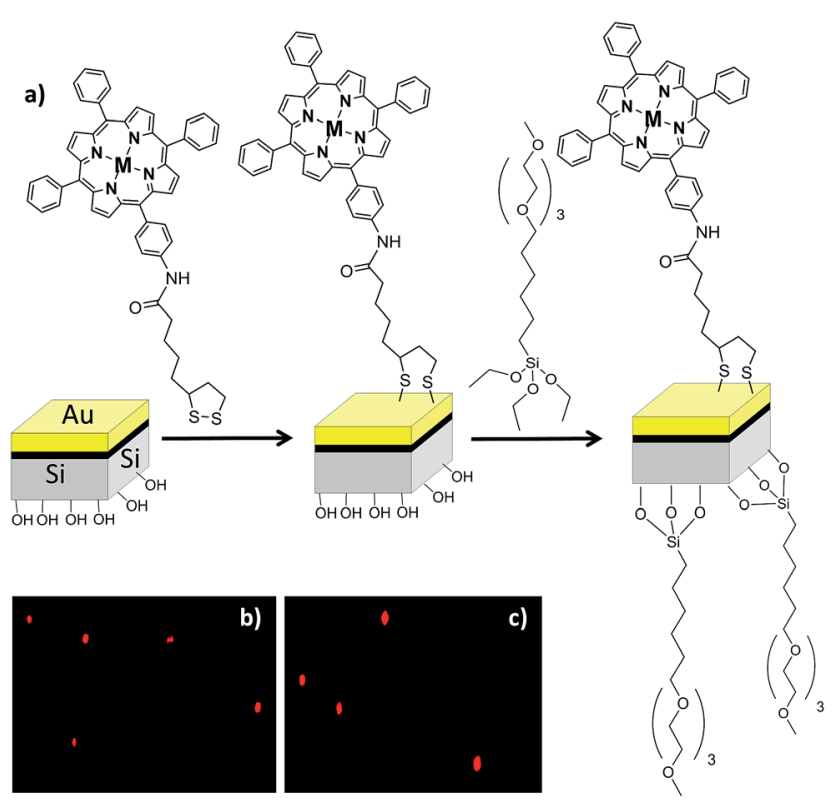

Fig. 6 Schematic representation of the $\mu \mathrm{P}$ functionalization with either ATTP-LA or ZnATPP-LA (a); fluorescence microscope images of bifunctional microparticles functionalized with ATPP-LA (b) and functionalized with ZnATPP-LA (c). 
with a range of $0.50-10 \mu \mathrm{m}$ of ATPP-LA or ZnATPP-LA (see ESI, Fig. S22 and S23, respectively $\dagger$ ). It was found that the samples of ATPP-LA- $\mu$ P contained $1.8 \mu \mathrm{M}$ ATPP-LA and the samples of ZnATPP-LA- $\mu$ P contained $1.4 \mu \mathrm{M}$ ZnATPP-LA. These concentrations correspond to suspensions of $500000 \mu \mathrm{Ps} \mathrm{mL}^{-1}$.

The geometric area for each vehicle was estimated from their dimensions, being $3.1 \times 10^{-4} \mu \mathrm{m}^{2}$ (GNP), $1.30 \mu \mathrm{m}^{2}$ (NR) and 9 $\mu \mathrm{m}^{2}(\mu \mathrm{P})$. In the case of the bifunctional $\mathrm{Si} / \mathrm{Au} \mu \mathrm{P}$, only the gold layer has been considered for the porphyrin adsorption. With these values, the content of porphyrin per $\mu \mathrm{m}^{2}$ could be calculated. In order to compare the amount of porphyrins incorporated in the different vehicles, the micromoles of porphyrin loaded in each vehicle was determined. A brief summary of the characteristics of all the vehicles, including their materials, shape, dimensions, and content in porphyrin per vehicle and per area, is presented in Table 1.

Due to the different size and shape of each carrier, the amount of PS molecules attached to the carrier was expected to be different. All the carriers retain porphyrin in the surface as a consequence of the bonds between the molecules and the superficial gold. The porphyrin/vehicle unit ratio increases in the sense GNP $<\mathrm{NR}<\mu \mathrm{P}$, due to the clear differences in the size of each vehicle. However, the amount of immobilized porphyrins is not directly proportional to the geometrical gold surface. When comparing the amount of linked porphyrin ATPP-LA by gold surface unit, we found a higher porphyrin/gold surface ratio for the $\mu \mathrm{P}\left(5.1 \times 10^{-10} \mu \mathrm{mol} \mu \mathrm{m}^{-2}\right)$ than for GNP $(9.0 \times$ $\left.10^{-11} \mu \mathrm{mol} \mu \mathrm{m}^{-2}\right)$ or NR $\left(2.6 \times 10^{-12} \mu \mathrm{mol} \mu \mathrm{m}^{-2}\right)$.

The same trend was observed for the vehicles loaded with ZnATPP-LA, where again the highest porphyrin/gold surface ratio was obtained for the $\mu \mathrm{P}\left(4.0 \times 10^{-10} \mu \mathrm{mol} \mu \mathrm{m}^{-2}\right)$, then for $\operatorname{GNP}\left(15.0 \times 10^{-11} \mu \mathrm{mol} \mu \mathrm{m}^{-2}\right)$ and the lowest for the NR $(2.6 \times$ $\left.10^{-12} \mu \mathrm{mol} \mu \mathrm{m}^{-2}\right)$. The NR present the lower porphyrin/gold surface ratio for both porphyrins, probably as a consequence of partial NR aggregation during the functionalization process. Although ultrasound conditions were used during functionalization, the relatively short PEG-derivative leads to low screening of the magnetic fields induced by the NR, and therefore not being able to prevent the formation of some aggregates that hinder the porphyrin adsorption over some parts of the NR surface.

Instead, the highest content for both porphyrins was found in the $\mu \mathrm{P}$, which can be justified by their bifunctional nature: the PEG-derivative used to make the particles more water- soluble and biocompatible was immobilized on the silicon face of the microparticles, whereas all the gold face remains free for the porphyrin chemisorption. Additionally, the gold layer is a rougher surface in the $\mu \mathrm{P}$, also contributing to a higher incorporation of porphyrin. For the other two types of vehicles, both porphyrin and PEG-derivative compete by the gold surface, forming a mixed SAM with both polyethyleneglycol and porphyrin molecules, and therefore the amount of porphyrins by gold area is lower.

\section{Singlet oxygen production quantification}

Singlet oxygen production was examined using the probe ABMA. In the presence of singlet oxygen, ABMA is converted into an endoperoxide, leading to a decrease in the fluorescence emission of the molecule due to photobleaching. ${ }^{67}$ The emission decay can be easily followed using fluorescence spectroscopy. To study de singlet oxygen production, the photosensitizer was irradiated in the presence of ABMA with a blue light source. It was verified that after 1 hour the decay of the fluorescence of the ABMA was low, and therefore the irradiation time was increased to 4 hours with continuous stirring, to obtain a cumulative effect where the difference between the different decay rates could be more noticeable. Fluorescence emission spectra were recorded every hour, in the range of 390$600 \mathrm{~nm}$, and the singlet oxygen production was determined by the decrease of the emission intensity of the ABMA (see ESI, Fig. S25 $\dagger$ ). A considerable decay of the ABMA fluorescence emission band during irradiation was observed, demonstrating the formation of the endoperoxide from the ABMA due to singlet oxygen production in all samples. A control sample containing ABMA solution without any porphyrin, irradiated under the same conditions, shows a negligible decay in the ABMA fluorescence emission. This result confirms that singlet oxygen was produced by the porphyrin derivatives, alone or loaded in the GNP, upon irradiation. It can be observed that after 4 hours the percentage of emission decay for ABMA in the presence of ATPP-LA, ATPP-LA, and ZnATPP-LA was 19\%, 17\% and $37 \%$ respectively, and for ATPP-LA-GNP and ZnATPP-LAGNP were $42 \%$ and $60 \%$, respectively, indicating the production of singlet oxygen in all cases (see Fig. S26 in ESI $\dagger$ ). It is also evident the differences in the ABMA fluorescence decay between the samples containing the porphyrins without metal (ATPP-LA and ATPP-LA) and those with the porphyrin containing zinc in

Table 1 Characterization of the three vehicles loaded with the porphyrins: the table shows the materials used in the procurement of the vehicles, their shape, dimensions, and content of porphyrin per vehicle unit

\begin{tabular}{|c|c|c|c|c|}
\hline Material & Shape and dimensions & Vehicle & $\begin{array}{l}\text { Porphyrin/vehicle } \\
\text { ( } \mu \mathrm{mol} / \mathrm{unit} \text { ) }\end{array}$ & $\begin{array}{l}\text { Porphyrin/area } \\
\left(\mu \mathrm{mol} \mu \mathrm{m}^{-2}\right)\end{array}$ \\
\hline Gold nanoparticle & Sphere $\varnothing=9-10 \mathrm{~nm}$ & $\begin{array}{l}\text { ATPP-LA-GNP } \\
\text { ZnATPP-LA-GNP }\end{array}$ & $\begin{array}{l}2.8 \times 10^{-14} \\
4.7 \times 10^{-14}\end{array}$ & $\begin{array}{l}9.0 \times 10^{-11} \\
15.0 \times 10^{-11}\end{array}$ \\
\hline Nanorod with gold shell and $\mathrm{Co} / \mathrm{Ni}$ core & Cylinder $\varnothing=110 \mathrm{~nm}, 3.7 \mu \mathrm{m}$ length & $\begin{array}{l}\text { ATPP-LA-NR } \\
\text { ZnATPP-LA-NR }\end{array}$ & $\begin{array}{l}3.4 \times 10^{-12} \\
5.0 \times 10^{-12}\end{array}$ & $\begin{array}{l}2.6 \times 10^{-12} \\
3.8 \times 10^{-12}\end{array}$ \\
\hline Gold and polysilicon microparticle & Cuboid $3 \mu \mathrm{m} \times 3 \mu \mathrm{m} \times 530 \mathrm{~nm}$ & $\begin{array}{l}\text { ATPP-LA- } \mu \text { P } \\
\text { ZnATPP-LA- } \mu \text { P }\end{array}$ & $\begin{array}{l}4.6 \times 10^{-9} \\
3.6 \times 10^{-9}\end{array}$ & $\begin{array}{l}5.1 \times 10^{-10} \\
4.0 \times 10^{-10}\end{array}$ \\
\hline
\end{tabular}


their core. This difference is associated to the presence of the zinc metal in the porphyrin molecule, which increases the capacity of the photosensitizer to generate singlet oxygen, as reported in the literature, ${ }^{\mathbf{1 2 , 6 8 , 6 9}}$ making this metalloporphyrin a promising PS for PDT. Finally, in order to compare the singlet oxygen production capacity of the free porphyrins (ATPP-LA, ATPP-LA and ZnATPP-LA) and of the porphyrins loaded in the GNP (ATPP-LA-GNP and ZnATPP-LA-GNP), the maximum rate of ABMA photobleaching was normalized with the concentration of the PS using eqn (1), where IF is the intensity of fluorescence.

$$
\frac{\left(\% \mathrm{IF}_{431} \text { at } t=0 \mathrm{~min}\right)-\left(\% \mathrm{IF}_{431} \text { at } t=60 \mathrm{~min}\right)}{60 \mathrm{~min} \times[\text { porphyrin }](\mu \mathrm{M})}
$$

The concentration of porphyrin in the solution was $3 \mu \mathrm{M}$, whether it was free in solution (ATPP-LA and ZnATPP-LA) or loaded in the GNP (ATPP-LA-GNP and ZnATPP-LA-GNP). All of the calculated maximum rates of ABMA photobleaching upon irradiation are compared in Fig. 7. The highest values of maximum rate of ABMA photobleaching, directly related to the singlet oxygen production, were obtained for both GNP $(0.055 \%$ and $0.066 \%$ fluorescence emission decay per min per $\mu \mathrm{M}$ for ATPP-LA-GNP and ZnATPP-LA-GNP, respectively). ATPP-LA 1 and ATPP-LA showed the lowest values $(0.027 \%$ and $0.033 \%$ fluorescence emission decay per min per $\mu \mathrm{m}$ respectively), while ZnATPP-LA shows a value of $\mathbf{0 . 0 5 0} \%$ fluorescence emission decay per min per $\mu \mathrm{M}$, which is lower than that obtained for ZnATPP-LA-GNP. It is noteworthy that the zinc-containing porphyrin ZnATPP-LA presents a maximum rate of ABMA photobleaching higher than the porphyrin without metal ATPP-LA when it was used alone or loaded in GNPs. This is in agreement with the fact that the zinc-containing porphyrin has a better capacity to produce singlet oxygen than the porphyrin without metal.

Moreover, when comparing the porphyrins ATPP-LA and ZnATPP-LA free in solution and loaded in the GNP, the increase observed in the rate of ABMA photobleaching is visible. These results demonstrate that the porphyrins resulted more effective when immobilized on GNP rather than free in solution, with an increased singlet oxygen production, a feature already observed

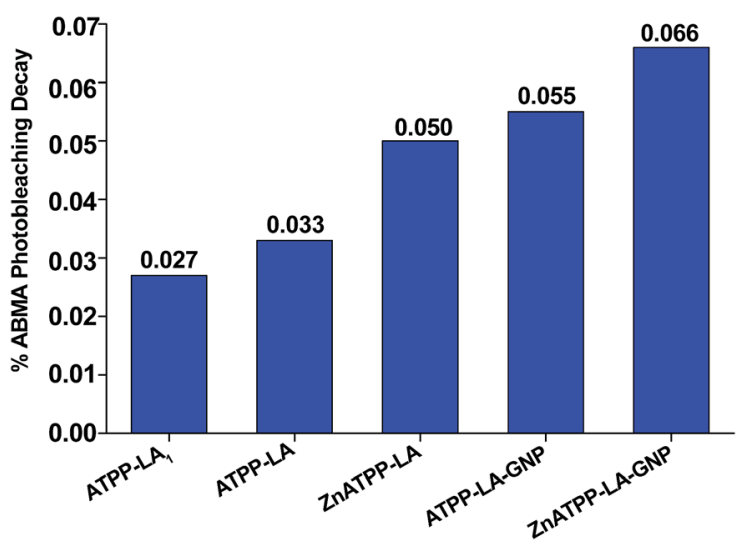

Fig. 7 Percentage rate of the photobleaching of ABMA at $431 \mathrm{~nm}$, normalized to porphyrin concentration. before for similar systems, ${ }^{15,27,70}$ which may be attributed to the high localized plasmonic field generated in the gold surface that enhances ROS production. ${ }^{27}$ This fact is even more remarkable considering that the photobleaching of the porphyrin-loaded GNP has been measured in aqueous solution, where oxygen is much less soluble and usually leads to a less significant effect for this type of measurement because of the shorter lifetime of singlet oxygen in water. ${ }^{71}$

\section{Cytotoxicity and photocytotoxicity studies}

Regarding the toxicity of the vehicles, previous studies with the NR functionalized with thiolated PEG allowed determining their biocompatibility. ${ }^{46}$ To assure that the GNP and the $\mu \mathrm{P}$ did not have intrinsic toxicity to the used cell lines, a viability study was also performed, both vehicles being coated with PEGcontaining thiol and no porphyrin. It was found that the viability of the cells was higher than $80 \%$ for the maximum concentrations tested of $100 \mathrm{nM}$ and $410000 \mu \mathrm{P} \mathrm{mL} \mathrm{mL}^{-1}$, respectively (see ESI Fig. S27 and S28†). This suggests that the thiol group which interacts with the gold surface does not exert a toxic effect on the cells. The cytotoxicity of porphyrins, both in solution and after immobilization in the different vehicles, was determined using HeLa cells. Porphyrins $\mathbf{T P P N H}_{2}$ and $\mathbf{Z n T P P N H}_{2}$ were used as controls in solution, rather than ATPPLA or ZnATPP-LA, because of their higher solubility in polar solvents. In this study, the manipulation of the cells was performed in the dark, so the results reflect the cytotoxicity in the absence of light irradiation and thus without singlet oxygen in the incubates. The purpose of this study was to find the adequate concentrations of porphyrins, free in solution and loaded in the different vehicles, at which HeLa cells viability was higher than $80-90 \%$ in the dark. The results obtained are shown in ESI Fig. S29-S32. $\dagger$ With these data, the maximum concentration of porphyrins, free or loaded in the carriers, were chosen to be used in the photocytotoxicity assays. Cytotoxicity follows a general trend, as the $\mathrm{Zn}$ containing porphyrins were more toxic than their non-metallated analogues, both in solution and after immobilization into the different vehicles. To study the photocytotoxicity, different porphyrin concentrations and light doses were used. The study was performed with HeLa cells and cell viability was determined for the free porphyrins $\mathbf{T P P N H}_{2}$ and $\mathbf{Z n T P P N H}_{2}$ (Fig. 8a and b) and for the porphyrins loaded in the three different vehicles: GNP (Fig. 9a and b), NR (Fig. 9c and d) and $\mu \mathrm{P}$ (Fig. 9e and f). The results obtained for the viability of HeLa cells in the presence of free porphyrins showed that in the dark (light dose $=0$ ) the survival cell fraction was higher than $95 \%$ for porphyrin concentrations up to $1 \mu \mathrm{M}$ and demonstrated that the incubation of HeLa cells with both porphyrins at the concentrations used did not induce significant cell death without irradiation.

More importantly, the results showed the concentration and light dose dependence of the photodynamic response of HeLa cells for both porphyrins (TPPNH $\mathbf{T H}_{2}$ and $\mathbf{Z n T P P N H}_{2}$ ). As expected, increasing the concentration of porphyrin and light dose causes an increase of photocytotoxicity. At the same porphyrin concentration and light dose, the photocytotoxic 


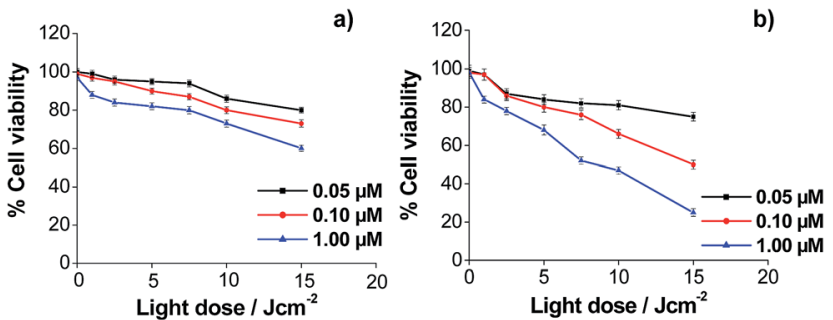

Fig. 8 HeLa cells viability (expressed in percentage with respect to controls) after irradiation at different light doses in the presence of: (a) TPPNH $_{2}$ and (b) $\mathrm{ZnTPPNH}_{2}$. The concentration of porphyrin in each incubate is the indicated in the figure. Control cells were incubated only with complete growth medium. The results displayed are the average values obtained by three independent experiments $(n=3)$ and the error bars correspond to standard deviation.
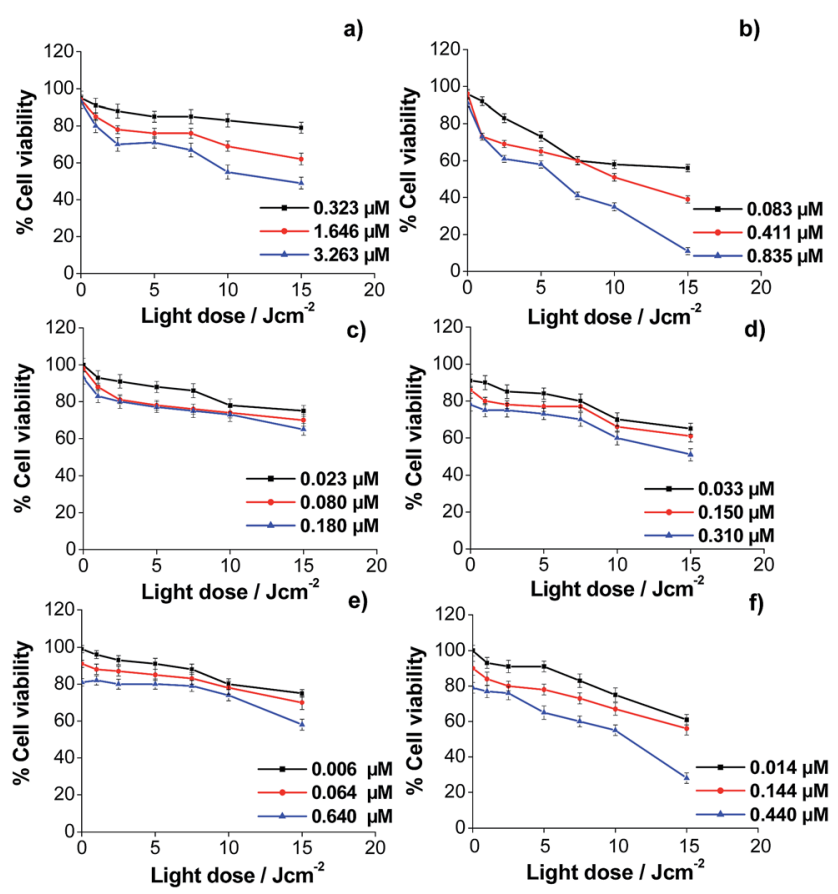

Fig. 9 HeLa cells viability (expressed in percentage with respect to controls) after irradiation at different light doses in the presence of: (a) ATPP-LA-GNP and (b) ZnATPP-LA-GNP; (c) ATPP-LA-NR and (d) ZnATPP-LA-NR; and (e) ATPP-LA- $\mu$ P and (f) ZnATPP-LA- $\mu$ P. The concentration of porphyrin in each incubate is the indicated in the figure. Control cells were incubated only with complete growth medium. The results displayed are the average values obtained by three independent experiments $(n=3)$ and the error bars correspond to standard deviation.

effect was more pronounced in the case of the metallated porphyrin (ZnATPP-LA), as expected by the increased production of singlet oxygen by this porphyrin, demonstrated by the increased ABMA photobleaching decay (Fig. 7). This result is in agreement with the production of singlet oxygen by related photosensitizers such as tetraphenylporphyrin and Zn(II)-tetraphenylporphyrin assessed by means of time-resolved nearinfrared phosphorescence detection. ${ }^{72}$ Using the non-cytotoxic highest porphyrin concentration $(1 \mu \mathrm{M})$ and light dose $15 \mathrm{~J}$ $\mathrm{cm}^{-2}$, the viability of HeLa cells was around $25 \%$ for $\mathbf{Z n T P P N H} \mathbf{H}_{2}$ which contrasts greatly with HeLa cells viability near $60 \%$ found for $\mathbf{T} \mathbf{P P N H} \mathbf{H}_{2}$, confirming the higher efficiency of $\mathbf{Z n T P P N H} \mathbf{H}_{\mathbf{2}}$, in accordance with the results obtained for other similar systems. ${ }^{12,68}$

Similar experiments were performed to demonstrate the usefulness of the synthesized porphyrin-loaded vehicles (with porphyrins bound to their gold surface) as efficient porphyrin carriers for PDT. It was observed that the global behaviour of HeLa cells incubated with both porphyrins loaded in the different vehicles is similar to that obtained for the free porphyrins. Also, HeLa cells viability decreases by increasing the porphyrin concentration in the incubation medium and the light dose used in the irradiation process. Moreover, for all vehicles, the effectiveness was higher when the porphyrin loaded was ZnATPP-LA. However, to analyze the results together and highlight the differences between the different vehicles it must be taken into account that while the light doses used were the same, the porphyrin concentration in the incubation medium varies according to their nature $\left(\mathbf{T P P N H}_{2}, \mathbf{Z n T P P N H} \mathbf{H}_{2}\right.$, or immobilized in the vehicles as ATPP-LA or ZnATPP-LA) and according to the vehicle used (GNP, NR or $\mu \mathrm{P}$ ). This difference is because: firstly, the number of ATPP-LA or ZnATPP-LA molecules in each vehicle varies (see Table 1) and, moreover, the inherent toxicity of the different vehicles determines its maximum concentration in the incubation medium in order to obtain a dark cytotoxicity (light dose $=0$ ) lower than $20 \%$ ( $\%$ cell viability $\geq 80 \%$ ). For this, it is necessary to compare the $\%$ of cell viability obtained at the same light dose and with a similar concentration of porphyrin.

The analysis of the results obtained for the photocytotoxicity of the porphyrins loaded in the GNP showed that the difference between the effectiveness of both porphyrins is even more evident. Thus, for both porphyrins at the maximum light dose, the cell viability using the ATPP-LA-GNP $([$ ATPP-LA $]=1.646 \mu \mathrm{M})$ was of $62 \%$ in relation to the control, whereas the use of ZnATPP-LA-GNP $([$ ZnATPP-LA $]=0.835 \mu \mathrm{M})$ caused a decrease in cell viability up to $11 \%$, even though the concentration of ZnATPP-LA was half of the ATPP-LA. Nevertheless, the enhancement in the photodynamic effect using the ZnATPP-LAGNP is greater than the increase in singlet oxygen production observed using the probe ABMA. It is interesting to note the increased phototoxicity for ZnATPP-LA observed when the porphyrin was added to the incubation medium loaded in the GNP, compared to the photocytotoxicity obtained for the free porphyrin. A similar concentration of free porphyrin $\left(\left[\mathbf{Z n T P P N H}_{2}\right]=1 \mu \mathrm{M}\right)$ causes less decrease of cell viability $(25 \%)$ than that produced by a concentration of $0.835 \mu \mathrm{M}$ of the porphyrin loaded in GNP ZnATPP-LA-GNP (11\%). The observed decrease in cell viability may be a consequence of a more favoured internalization of the porphyrins into HeLa cells when they were supported on the GNP (see later).

In the case of the NR, the tested amounts of the porphyrins in the cell viability experiments were greatly limited by the higher toxicity of the material. Therefore, the concentration of both porphyrins in the incubation media was lower than that used for the other vehicles (GNP and $\mu \mathrm{P}$ ). In this case, it was 
observed that for similar porphyrin concentrations ([ATPP-LA] $=0.180 \mu \mathrm{M}$; [ZnATPP-LA $]=0.150 \mu \mathrm{M}$ ) and the maximum light dose, the cell viability using ATPP-LA-NR or ZnATPP-LA-NR was similar. On the other hand, in both cases the decrease in cell viability with the increase in porphyrin concentration is less pronounced than for free porphyrins or loaded in the other two vehicles. Moreover, at similar porphyrin concentrations and light dose, the effectiveness in cell toxicity was similar for free porphyrins and loaded in NR. One possible explanation may be the difficulty of NR to enter the cells causing a reduced availability of porphyrins as in the other cases (see later). This may be because of their size and tendency to aggregate, reducing the uptake of the NR by HeLa cells. To overcome this difficulty, the design of the vehicle may be changed by introducing a PEGcontaining derivative with higher molecular weight, to improve their dispersion in water and to prevent their aggregation.

Finally, for the ATPP-LA- $\mu \mathbf{P}$, the percentage of cell viability $(65 \%)$ obtained for a [ATPP-LA $]=1.840 \mu \mathrm{M}$, after the photodynamic treatment, is comparable with that obtained (62\%) for a similar concentration of the same porphyrin ([ATPP-LA $]=$ $1.646 \mu \mathrm{M})$ immobilized in the GNP. However when comparing the photocytotoxic effect of ZnATPP-LA loaded in the $\mu \mathrm{P}$ (ZnATPP-LA- $\mu$ P, Fig. 9f) and in the GNP (ZnATPP-LA-GNP, Fig. 9b), it can be observed that the highest concentration of ZnATPP-LA $(1.440 \mu \mathrm{M})$ used for $\mu$ Ps leads to a $28 \%$ of cell viability at the maximum dose of irradiation, while a lower concentration of the same porphyrin ([ZnATPP-LA $]=0.835 \mu \mathrm{M})$ loaded in the GNP, at the same dose of light, leads to a lower percentage of cell viability $(11 \%)$, indicating the higher phototoxic efficiency of ZnATPP-LA-GNP versus ZnATPP-LA- $\mu$ P, probably as a consequence of the higher cellular uptake in the GNP.

\section{Internalization study of the ZnATPP-LA-containing vehicles}

To enlighten the photocytotoxicity results, the internalization by HeLa cells of the different porphyrin-loaded vehicles was assessed to determine whether the vehicles enter the cells or not. Because the amount of porphyrin immobilized per area of vehicle is different in each case, the intensity of the observed fluorescence cannot be directly correlated with the amount of vehicle entering the cells. Since the higher efficiency in the photodynamic effect was obtained with the zinc-containing porphyrin, this study was carried out for ZnATPP-LA-GNP, ZnATPP-LA-NR and ZnATPP-LA- $\boldsymbol{\mu P}$. Therefore, HeLa cells were incubated with these systems for 24 hours, and then labelled with the cytoplasm marker CMFDA, which shows fluorescence by action of esterases present inside the cell. Fig. 10 shows the confocal images corresponding to a central plane of HeLa cells, depicting images corresponding to the green fluorescence of the cell marker, the red images for the vehicles loaded with the porphyrin, and a merged image of the previous two. 3D reconstruction of the confocal images is available (see ESI, $\uparrow$ multimedia files 01_GNP_3D, 02_uP_3D and 03_NR_3D).

It can be observed that the amount of ZnATPP-LA-GNP which is able to enter into HeLa cells is high, and that they are found inside most of the cells. Thus, despite that ZnATPP-LA-GNP

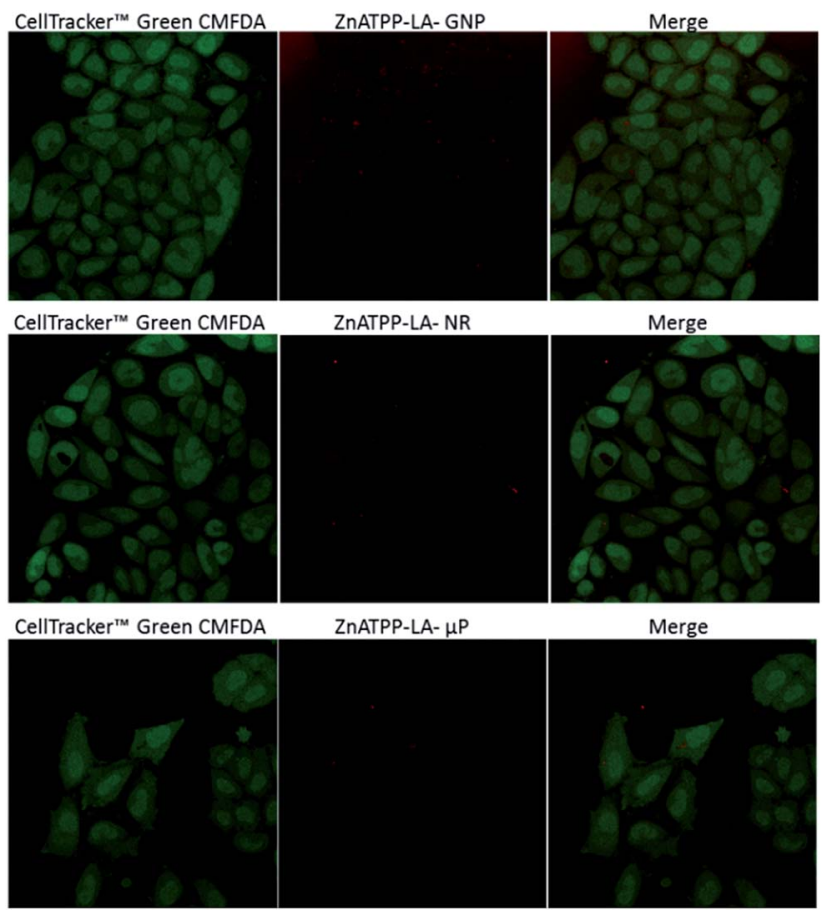

Fig. 10 Internalization of ZnATPP-LA-GNP, ZnATPP-LA-NR and ZnATPP-LA- $\mu$ P into HeLa cells. HeLa cells were also loaded with the cytoplasmic Cell TrackerTM Green CMFDA. The cytoplasm is shown in green (left column), the red images (middle column) correspond to the porphyrin-loaded carriers and the right column shows their overlay. The images correspond to sections chosen from a middle plane of the cells. 3D reconstructions are available as multimedia files (see ESI $\dagger$ ).

have the least porphyrin load per vehicle unit $\left(7.0 \times 10^{-14} \mu \mathrm{mol}\right.$ per GNP), the fact that their uptake by HeLa cells is high helps to explain why, at the same concentration of porphyrin, its photocytotoxicity is greater. The images for HeLa cells incubated with ZnATPP-LA-NR shows the presence of some aggregates, which are mainly outside the cells, and this result explain their low photocytotoxicity; the small amount of ZnATPP-LA-NR inside the cells determines that the intracellular porphyrin content is low, and consequently the concentration of singlet oxygen inside the cells is also small. On the other hand, even though for NR the area/volume ratio is high, the aggregation of NR could shield the porphyrin molecules. This fact could prevent the molecules from generating singlet oxygen during the irradiation process, and thus would explain the lower photocytotoxicity found. Thus, it is necessary to improve their design, as discussed in the previous section, to favour the capture of NR by HeLa cells, increasing the content of porphyrin within cells and improving the photocytotoxicity for ZnATPPLA-NR. The confocal images of HeLa cells incubated with ZnATPP-LA- $\mu$ P indicate a low uptake. The different uptake of NR and $\mu \mathrm{P}$ in relation to that of GNP suggests that the smaller dimensions of the later (see Table 1) facilitated the uptake by the HeLa cells, aided by their higher solubility.

Moreover, it must be taken into account the amount of each porphyrin loaded into each carrier. In this sense, it can be stand out that $\mu \mathrm{P}$ hold the greater amount of porphyrins while gold 
nanoparticles contain the least amount. The observed uptake for $\mu \mathrm{P}$ does not correlate well with the results of their photocytotoxicity. It would be expected that the low amount of $\mu \mathrm{P}$ inside HeLa cells and the fact that there are few cells containing $\mu \mathrm{P}$, would be related to a lower photocytotoxicity as it occurs when using NR. However, looking at the concentration of porphyrin ZnATPP-LA that was added to the incubation medium as ZnATPP-LA-GNP, ZnATPP-LA-NR or ZnATPP-LA- $\mu$ P, the results show that at comparable concentrations of porphyrin, the photocytotoxicity of ZnATPP-LA- $\mu$ P is intermediate between that of the other two formulations, being higher when using ZnATPP-LA-GNP. This result may be related to the fact that, in the case of ZnATPP-LA- $\boldsymbol{\mu P}$ the content of porphyrin per carrier unit is about 106 times higher than that of the ZnATPP-LA-GNP and of 103 times higher than that of the ZnATPP-LA-NR, so that the photocytotoxicity would not depend only of the amount of the internalized carrier if not mainly of the total porphyrin content within the cells.

\section{Conclusion}

In this work three different nanostructured systems have been used all having a common aspect: a gold surface for easy functionalization with porphyrins containing disulphide groups. The porphyrins in solution and the porphyrins incorporated in the vehicles did not show cytotoxicity in the dark but showed good photocytotoxic effect in HeLa cells when irradiated with light. In all cases, the zinc-containing porphyrins had higher effect upon light irradiation. The NR showed the less cytotoxic effect for the studied concentrations, which were low because of their intrinsic toxicity and magnetic aggregation, being a possible explanation for the lower effectiveness observed. To improve the design of the $\mathrm{NR}$, a thicker hydrophilic layer could be created around them, to prevent its aggregation and to make them more biocompatible. $\mu \mathrm{P}$ load the higher amount of porphyrin molecules per carrier unit, which can explain the considerable cytotoxicity observed even though the uptake is not so high. Due to their bifunctional nature, they can be conjugated with internalization agents, such as transferrin or cell-penetrating peptides, to overcome their low uptake. GNP had the better photocytotoxicity results, showing higher effect with regard to that of free porphyrin in solution, as also observed in the ABMA photobleaching, meaning that the porphyrin immobilized on the GNP had an enhancement in its effect. The design of the nanostructures influenced the amount of porphyrin incorporated per vehicle and per area, which had consequences in the internalization ability of the system and in the efficiency of the porphyrins upon irradiation. We are currently testing new strategies to formulate the carriers including the incorporation of recognition ligands to receptors overexpressed in specific tumour cells to direct the vehicles and help their internalization by endocytosis.

\section{Acknowledgements}

This work was supported by the EU ERDF (FEDER) funds and the Spanish Government grant TEC2014-51940-C2. The LED source for PDT treatment was purchased with a grant from the
Spanish Government (CTQ2013-48767-C3-1-R). M.E.A.-R. thanks the UB for a predoctoral grant.

\section{Notes and references}

1 I. J. MacDonald and T. J. Dougherty, J. Porphyrins Phthalocyanines, 2001, 5, 105-129.

2 D. Phillips, Photochem. Photobiol. Sci., 2010, 9, 1589-1596.

3 P. Agostinis, K. Berg, K. A. Cengel, T. H. Foster, A. W. Girotti, S. O. Golinick, S. M. Hahn, M. R. Hamblin, A. Juzeniene, D. Kessel, M. Korbelik, J. Moan, P. Mroz, D. Nowis, J. Piette, B. C. Wilson and J. Golab, Ca-Cancer J. Clin., 2011, 61, 250-281.

4 M. Mitsunaga, M. Ogawa, N. Kosaka, L. T. Rosenblum, P. L. Choyke and H. Kobayashi, Nat. Med., 2011, 17, 1685-1691. 5 J. M. Dabrowski, M. Krzykawska, L. G. Arnaut, M. M. Pereira, C. J. P. Monteiro, S. Simoes, K. Urbanska and G. Stochel, ChemMedChem, 2011, 6, 1715-1726.

6 C. Wang, L. Cheng and Z. Liu, Theranostics, 2013, 3, 317-330. 7 L. J. Zhang, D. O'Shea, C. Y. Zhang, Y. J. Yan, L. Wang and Z. L. Chen, J. Cancer Res. Clin. Oncol., 2015, 141, 1921-1930. 8 J. Kim, H. Fijioka, N. L. Oleinick and V. E. Anderson, Free Radical Biol. Med., 2010, 49, 726-732.

9 R. Liang, R. Tian, L. Ma, L. Zhang, Y. Hu, J. Wang, M. Wei, D. Yan, D. G. Evans and X. Duan, Adv. Funct. Mater., 2014, 24, 3144-3151.

10 J. M. Dabrowski, M. M. Pereira, L. G. Arnaut, C. J. P. Monteiro, A. F. Peixoto, A. Karocki, K. Urbanska and G. Stochel, Photochem. Photobiol., 2007, 83, 897-903.

11 J.-X. Zhang, J.-W. Zhou, C.-F. Chan, T. C.-K. Lau, D. W. J. Kwong, H.-L. Tam, N.-K. Mak, K.-L. Wong and W.-K. Wong, Bioconjugate Chem., 2012, 23, 1623-1638.

12 P. M. Antoni, A. Naik, I. Albert, R. Rubbiani, S. Gupta, P. Ruiz-Sanchez, P. Munikorn, J. M. Mateos, V. Luginbuehl, P. Thamyongkit, U. Ziegler, G. Gasser, G. Jeschke and B. Spingler, Chem.-Eur. J., 2015, 21, 11791183.

13 D. K. Chatterjee, L. S. Fong and Y. Zhang, Adv. Drug Delivery Rev., 2008, 60, 1627-1637.

14 L. Smith, Z. Kuncic, K. Ostrikov and S. Kumar, J. Nanomater., 2012, 7, 2012.

15 O. Penon, M. J. Marín, D. B. Amabilino, D. A. Russell and L. Pérez-García, J. Colloid Interface Sci., 2016, 462, 154-165.

16 P. Couleaud, V. Morosini, C. Frochot, S. Richeter, L. Raehm and J.-O. Durand, Nanoscale, 2010, 2, 1083-1095.

17 K. Hayashi, M. Nakamura, H. Miki, S. Ozaki, M. Abe, T. Matsumoto, T. Kori and K. Ishimura, Adv. Funct. Mater., 2014, 24, 503-513.

18 S. H. Voon, L. V. Kiew, H. B. Lee, S. H. Lim, M. I. Noordin, A. Kamkaew, K. Burgess and L. Y. Chung, Small, 2014, 10, 4993-5013.

19 C. He, D. Liu and W. Lin, ACS Nano, 2015, 9, 991-1003.

20 A. Kamkaew, F. Chen, Y. Zhan, R. L. Majewski and W. Cai, ACS Nano, 2016, 10, 3918-3935.

21 R. Di Corato, G. Béalle, J. Kolosnjaj-Tabi, A. Espinosa, O. Clément, A. K. A. Silva, C. Ménager and C. Wilhelm, ACS Nano, 2015, 9, 2904-2916. 
22 R. Vankayala, Y. K. Huang, P. Kalluru, C. S. Chiang and K. C. Hwang, Small, 2014, 10, 1612-1622.

23 J. Shan, S. J. Budijono, G. Hu, N. Yao, Y. Kang, Y. Ju and R. K. Prud'Homme, Adv. Funct. Mater., 2011, 21, 2488-2495.

24 O. Penon, T. Patiño, L. Barrios, C. Nogués, D. B. Amabilino, K. Wurst and L. Pérez-García, ChemistryOpen, 2015, 4, 127136.

25 M. Camerin, M. Magaraggia, M. Soncin, G. Jori, M. Moreno, I. Chambrier, M. J. Cook and D. A. Russell, Eur. J. Cancer, 2010, 46, 1910-1918.

26 K. Zaruba, J. Kralova, P. Rezanka, P. Pouckova, L. Veverkova and V. Kral, Org. Biomol. Chem., 2010, 8, 3202-3206.

27 M. K. K. Oo, Y. Yang, Y. Hu, M. Gomez, H. Du and H. Wang, ACS Nano, 2012, 6, 1939-1947.

28 E. Boisselier and D. Astruc, Chem. Soc. Rev., 2009, 38, 17591782.

29 S. Rana, A. Bajaj, R. Mout and V. M. Rotello, Adv. Drug Delivery Rev., 2012, 64, 200-216.

30 R. Mout, D. F. Moyano, S. Rana and V. M. Rotello, Chem. Soc. Rev., 2012, 41, 2539-2544.

31 T. Stuchinskaya, M. Moreno, M. J. Cook, D. R. Edwards and D. A. Russell, Photochem. Photobiol. Sci., 2011, 10, 822-831.

32 G. Obaid, I. Chambrier, M. J. Cook and D. A. Russell, Photochem. Photobiol. Sci., 2015, 14, 737-747.

33 M. Lattuada and T. A. Hatton, Nano Today, 2011, 6, 286-308. 34 J. Gao, H. Gu and B. Xu, Acc. Chem. Res., 2009, 42, 1097-1107. 35 Y. Yang and C. Yu, Nanomedicine, 2015, 12, 317-332.

36 C.-Y. Wen, H.-Y. Xie, Z.-L. Zhang, L.-L. Wu, J. Hu, M. Tang, M. Wu and D.-W. Pang, Nanoscale, 2016, 8, 12406-12429.

37 H. Liu, J. Zhang, X. Chen, X.-S. Du, J.-L. Zhang, G. Liu and W.-G. Zhang, Nanoscale, 2016, 8, 7808-7826.

38 N. Torras, J. P. Agusil, P. Vázquez, M. Duch, A. M. Hernández-Pinto, J. Samitier, E. J. de la Rosa, J. Esteve, T. Suárez, L. Pérez-García and J. A. Plaza, Adv. Mater., 2016, 28, 1449-1454.

39 R. E. Serda, J. Gu, R. C. Bhavane, X. Liu, C. Chiappini, P. Decuzzi and M. Ferrari, Biomaterials, 2009, 30, 2440-2448.

40 B. D. Chithrani, A. A. Ghazani and W. C. W. Chan, Nano Lett., 2006, 6, 662-668.

41 Y. Qiu, Y. Liu, L. Wang, L. Xu, R. Bai, Y. Ji, X. Wu, Y. Zhao, Y. Li and C. Chen, Biomaterials, 2010, 31, 7606-7619.

42 S. E. A. Gratton, P. A. Ropp, P. D. Pohlhaus, J. C. Luft, V. J. Madden, M. E. Napier and J. M. DeSimone, Proc. Natl. Acad. Sci. U. S. A., 2008, 105, 11613-11618.

43 X. Huang, X. Teng, D. Chen, F. Tang and J. He, Biomaterials, 2010, 31, 438-448.

44 N. Hao, L. Li, Q. Zhang, X. Huang, X. Meng, Y. Zhang, D. Chen, F. Tang and L. Li, Microporous Mesoporous Mater., 2012, 162, 14-23.

45 B. Duncan, C. Kim and V. M. Rotello, J. Controlled Release, 2010, 148, 122-127.

46 C. Gispert, A. Serrà, M. E. Alea, M. Rodrigues, E. Gómez, M. Mora, M. L. Sagristá, L. Pérez-García and E. Vallés, Electrochem. Commun., 2016, 63, 18-21.

47 A. Serrà, N. Gimeno, E. Gómez, M. Mora, M. L. Sagristá and E. Vallés, Adv. Funct. Mater., 2016, 26, 6601-6611.
48 S. Durán, M. Duch, T. Patiño, A. Torres, O. Penon, R. GómezMartínez, L. Barrios, J. Esteve, C. Nogués, L. Pérez-García and J. A. Plaza, Sens. Actuators, B, 2015, 209, 212-224.

49 T. Patiño, J. Soriano, E. Amirthalingam, S. Durán, A. González-Campo, M. Duch, E. Ibáñez, L. Barrios, J. A. Plaza, L. Pérez-García and C. Nogués, Nanoscale, 2016, 8, 8773-8783.

50 S. Hassan, Y. Zhou, L. Zhang, Z. Shi, D. Yang and N. Qu, J. Phys. Chem. C, 2016, 120, 7757-7766.

51 S. Weimin, S. Qi, W. Yucheng, L. Lihong and T. Jingchao, J. Heterocycl. Chem., 2010, 47, 1221-1224.

52 A. D. Adler, F. R. Longo, J. D. Finarelli, J. Goldmacher, J. Assour and L. Korsakoff, J. Org. Chem., 1967, 32, 476.

53 W. J. Kruper Jr, T. A. Chamberlin and M. Kochanny, J. Org. Chem., 1989, 54, 2753-2756.

54 Y. Dong, S. Abaci, C. Shannon and M. J. Bozack, Langmuir, 2003, 19, 8922-8926.

55 Y. Dong and C. Shannon, Anal. Chem., 2000, 72, 2371-2376. 56 P. D. Beer, D. P. Cormode and J. J. Davis, Chem. Commun., 2004, 44, 414-415.

57 J. P. Mattos-Almeida, E. R. Figueroa and R. A. Drezek, Nanomedicine, 2014, 10, 503-514.

58 R. Cao-Milán and L. M. Liz-Marzán, Expert Opin. Drug Delivery, 2014, 11, 741-752.

59 M. Brust, M. Walker, D. Bethell, D. J. Schiffrin and R. Whyman, J. Chem. Soc., Chem. Commun., 1994, 801-802.

60 T. Yonezawa, K. Yasui and N. Kimizuka, Langmuir, 2001, 17, 271-273.

61 L. Srisombat, A. C. Jamison and T. R. Lee, Stability, Colloids Surf., A, 2011, 390, 1-19.

62 Z. Tang, T. Ahuja, S. Wang and G. Wang, Nanoscale, 2012, 4, 4119-4124.

63 E. Boix-Garriga, P. Acedo, A. Casadó, A. Villanueva, J. C. Stockert, M. Cañete, M. Mora, M. L. Sagristá and S. Nonell, Nanotechnology, 2015, 26, 365104.

64 W. Zheng, N. Shan, L. Yu and X. Wang, Dyes Pigm., 2008, 77, 153-157.

65 V. V. Apanasovich, E. G. Novikov, N. N. Yatskov, R. B. M. Koehorst, T. J. Schaafsma and A. van Hoek, J. Appl. Spectrosc., 1999, 66, 613-616.

66 W. Haiss, N. T. K. Thanh, J. Aveyard and D. G. Fernig, Anal. Chem., 2007, 79, 4215-4221.

67 M. Wang, L. Huang, S. K. Sharma, S. Jeon, S. Thota, F. F. Sperandio, S. Nayka, J. Chang, M. R. Hamblin and L. Y. Chiang, J. Med. Chem., 2012, 55, 4274-4285.

68 B. R. Vummidi, F. Noreen, J. Alzeer, K. Moelling and N. W. Luedtke, ACS Chem. Biol., 2013, 8, 1737-1746.

69 O. Viana, M. Ribeiro, A. Rodas, J. Rebouças, A. Fontes and B. Santos, Molecules, 2015, 20, 8893-8912.

70 R. Lin, L. Zhou, Y. Lin, A. Wang, J. H. Zhou and S. H. Wei, Spectroscopy, 2011, 26, 179-185.

71 R. Battino, T. R. Rettich and T. Tominaga, J. Phys. Chem. Ref. Data, 1983, 12, 163-178.

72 F. Postigo, M. Mora, M. A. de Madariaga, S. Nonell and M. L. Sagristá, Int. J. Pharm., 2004, 278, 239-254. 